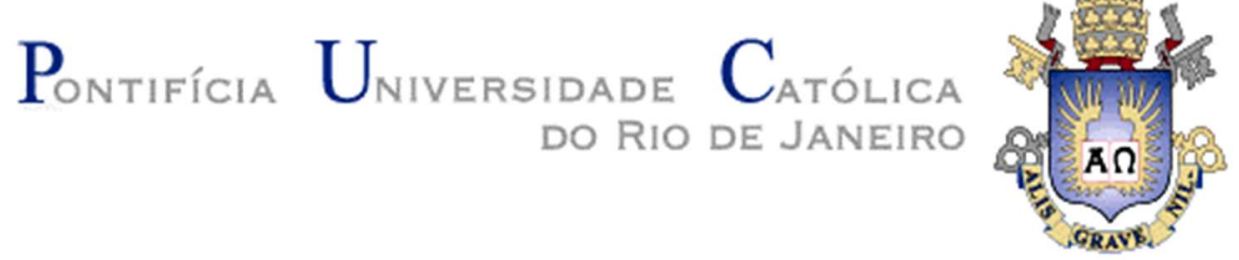

Raquel Barbosa Monteiro Vianna

\title{
OPÇÃO REAL DE UM PROJETO IMOBILIARIO RESIDENCIAL
}

\section{Dissertação de Mestrado}

Dissertação apresentada como requisito parcial para obtenção do título de Mestre pelo Programa de Pós-graduação em Administração de Empresas do departamento IAG da PUC-Rio.

Orientador: Prof. Luiz Eduardo Brandão 


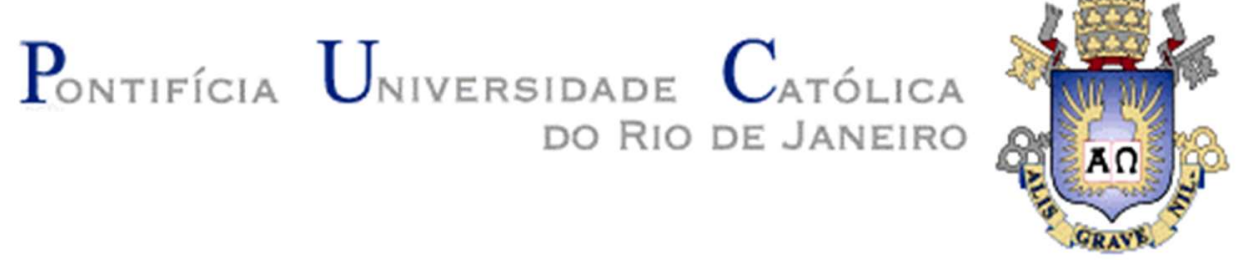

Raquel Barbosa Monteiro Vianna

\title{
OPÇÃO REAL DE UM PROJETO IMOBILIARIO RESIDENCIAL
}

Dissertação apresentada como requisito parcial para obtenção do grau de Mestre pelo Programa de Pós-Graduação em Administração de Empresas da PUC-Rio. Aprovada pela Comissão Examinadora abaixo.

\author{
Profo. Luiz Eduardo Brandão \\ Orientador \\ Departamento de Administração - PUC-RIO \\ Prof ${ }^{\mathrm{a}}$ Graziela Fortunato \\ Departamento de Administração - PUC-RIO
}

Profo. Ricardo Bordeaux Rêgo

UFF

Rio de Janeiro, 30 de julho de 2021. 
Todos os direitos reservados. É proibida a reprodução total ou parcial do trabalho sem autorização da universidade, da autora e do orientador.

\section{Raquel Barbosa Monteiro Vianna}

Graduou-se em Licenciatura em Matemática pela Universidade Estadual do Rio de Janeiro (UERJ), em 2009 e em Administração de Empresas pela Pontifícia Universidade Católica do Rio de Janeiro (PUC-RIO), em 2011. Concluiu MBA Executivo em Finanças em 2014 pela IBMEC-RJ e possui 12 anos de experiência em mercado imobiliário.

Ficha Catalográfica

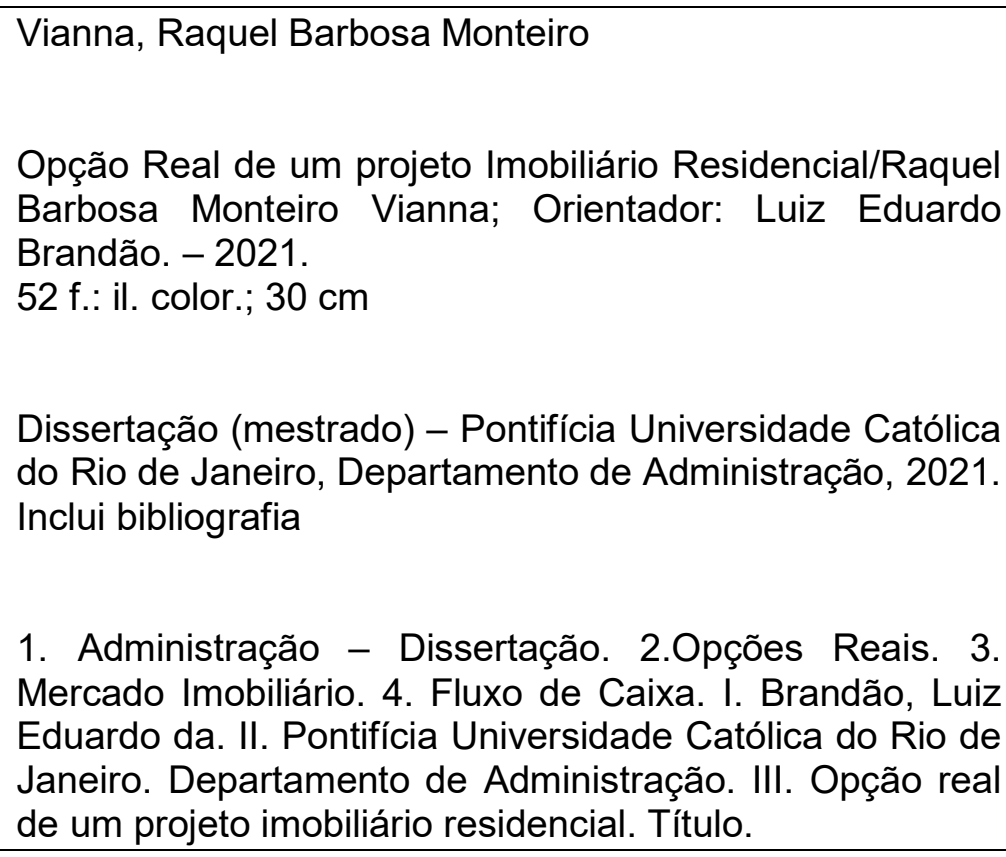

Opção Real de um projeto Imobiliário Residencial/Raquel Barbosa Monteiro Vianna; Orientador: Luiz Eduardo Brandão. - 2021.

52 f.: il. color.; $30 \mathrm{~cm}$

Dissertação (mestrado) - Pontifícia Universidade Católica do Rio de Janeiro, Departamento de Administração, 2021. Inclui bibliografia

1. Administração - Dissertação. 2.Opções Reais. 3. Mercado Imobiliário. 4. Fluxo de Caixa. I. Brandão, Luiz Eduardo da. II. Pontifícia Universidade Católica do Rio de Janeiro. Departamento de Administração. III. Opção real de um projeto imobiliário residencial. Título. 


\section{AGRADECIMENTOS}

Primeiramente gostaria de agradecer ao meu orientador, Professor Luiz Eduardo Teixeira Brandão, por toda a paciência, dedicação e generosidade em me orientar. Ser professor é um dom e ele é o melhor exemplo que já pude conviver nessa minha trajetória.

Também gostaria de agradecer a minha família por todo o apoio em realizar mais um sonho. Em especial ao meu marido, Vitor, que sempre esteve do meu lado, me incentivando e apoiando a evoluir.

A todos aos meus amigos que conheci nesse curso de mestrado. Conhecer cada um de vocês foi essencial para minha caminhada e evolução profissional e pessoal.

Gostaria de deixar minha gratidão a todos aos professores que me presentearam com seus conhecimentos e ensinamentos. Aos colaboradores, secretários e recepcionistas do IAG que sempre me atenderam com muito carinho. Realmente a equipe do IAG/PUC-RIO é excepcional.

A empresa que trabalho atualmente e a todos as pessoas da minha equipe, pela paciência e compreensão nesses últimos anos.

A todos os meus amigos por estarem ao meu lado em todos os momentos.

E, por último, mas não menos importante, à Deus, que vem sempre iluminando meus passos.

O presente trabalho foi realizado com apoio da Coordenação de Aperfeiçoamento de Pessoal de Nível Superior - Brasil (CAPES) - Código de Financiamento 001 . 


\section{RESUMO}

Vianna, Raquel Barbosa Monteiro; Brandão, Luiz Eduardo. Opção Real de um projeto imobiliário residencial. Rio de Janeiro, 2021. 52 p. Dissertação de Mestrado - Departamento de Administração, Pontifícia Universidade Católica do Rio de Janeiro.

Como em qualquer outro setor, o da construção civil tem a necessidade de aprimorar seus processos e de criar diferencias perante seus concorrentes, com a finalidade de aumentar os lucros e minimizar os prejuízos. Em função disso, a alta gerencia busca soluções para que a sua empresa se destaque no mercado. Os modelos tradicionais de avaliação de investimentos, como a metodologia do fluxo de caixa descontado (FCD), não consideram as incertezas e as flexibilidade inseridas no mercado. Visando isso, esse trabalho, será analisado, pela ótica das Opções Reais, uma maneira de minimizar os riscos de um projeto residencial através da determinação do momento ótimo de expandi-lo. Para tanto, serão utilizados os dados de um empreendimento residencial localizado na zona oeste da cidade do Rio de Janeiro, em que será submetido a um modelo baseado nas diretrizes das Opções Reais. Os resultados obtidos nos três cenários analisados no modelo numérico indicam que quando a velocidade de vendas é constante, o mais indicado é adiar ao máximo o momento de expansão do projeto uma vez que isso adia os custos do investimento e aumenta as receitas.

\section{Palavras-chave}

Opções Reais - Mercado imobiliário - Construção Civil - Fluxo de caixa 


\section{ABSTRACT}

Vianna, Raquel Barbosa Monteiro; Brandão, Luiz Eduardo (Adivisor). Real options of a residential real estate project. Rio de Janeiro, 2021. 52 p. Dissertação de Mestrado - Departamento de Administração, Pontifícia Universidade Católica do Rio de Janeiro.

As in any other sector, the construction industry needs to improve its processes and create differentiations in the face of its competitors, in order to increase profits and minimize losses. Because of this, top management seeks solutions to make their company stand out in the market. Traditional capital budgeting evaluation models, such as the Discounted Cash Flow (DCF) method, do not consider the value of the uncertainties and the flexibility that may exist in the project. With this in mind, this paper analyzes, through the Real Options approach, a way to minimize the risks of a residential project by determining the optimal time to expand it. To this end, we will use data from a residential development located in the western zone of the city of Rio de Janeiro, which will be submitted to a model based on Real Options guidelines. The results obtained in the three scenarios analyzed in the numerical model indicate that when the sales velocity is constant, it is best to defer the expansion as long as possible since this postpones the investment costs and increases the revenues.

\section{KEYWORDS}

Real Options - Real estate market - Construction industry - Cash Flow 


\section{SUMÁRIO}

1 INTRODUÇÃO

2 REVISÃO DA LITERATURA

2.2 OPÇÕES REAIS 14

2.2.1 MÉTODOS DE AVALIAÇÃO DE OPÇÕES REAIS 17

2.3 OPÇÕES REAIS NO MERCADO IMOBILIÁRIO 20

3 CONTEXTUALIZACAO 23

3.1 O MERCADO IMOBILIÁRIO 23

4 ESTUDO DE CASO 31

5 RESULTADOS $\quad 41$

6 CONCLUSÃO

7 BIBLIOGRAFIA $\quad 46$

ANEXO A: FLUXO DE CAIXA - CENÁRIO OTIMISTA 50

ANEXO B: FLUXO DE CAIXA - CENÁRIO ESPERADO 51

ANEXO C: FLUXO DE CAIXA - CENÁRIO PESSIMISTA 52 


\section{FIGURAS}

FIgURA 1 - QUADRO COMPARATIVO ENTRE OPÇÕES FINANCEIRAS E OPÇÕES REAIS. $\quad 14$

FIGURA 2 - GRÁFICO DO VALOR DA OPÇÃO 16

FIGURA 3 - EXEMPLO DA ESTRUTURA DE UM MODELO BINOMIAL. 19

FIGURA 4 - EVOLUÇÃO DOS PRINCIPAIS ÍNDICES UTILIZADOS NO MERCADO IMOBILIÁRIO. 26

FIGURA 5 - IMÓVEIS NEGOCIADOS NA CIDADE DO RIO DE JANEIRO. 27

FIGURA 6 - VENDAS DE UNIDADES RESIDENCIAIS DE 2019 E 2020

FIGURA 7 - EVOLUÇÃO dOS ÚLTIMOS 12 MESES DOS PRINCIPAIS ÍNDICES DO MERCADO IMOBILIÁRIO 28

FIGURA 8 - LANÇAMENTO DE UNIDADES RESIDÊNCIAS DE 2019 E 2020

FIGURA 9 - COMPARATIVO ENTRE UNIDADES LANÇADAS E VENDIDAS 29

FIGURA 10 - CENÁRIOS ANALISADOS. 34

FIGURA 11 - ESTRUTURA DO MODELO NO DPL TM 41

FIGURA 12 - PROBABILIDADE DAS DECISÕES DOS PERÍODOS $7^{\circ}$ AO $18^{\circ}$ NOS TRÊS CENÁRIO. $\quad 41$

FIGURA 13 - COMPARATIVO DOS VPL'S EM CADA CENÁRIO.

42 


\section{TABELAS}

TABELA 1 - DiVISÃO dO CONDOMÍNIO RESIDENCIAL X POR TIPOLOGIA E FASE DE LANÇAMENTO.

TABELA 2 - OS TRÊS CENÁRIOS ESCOLHIDOS. 33

TABELA 3 - PRÊMIO DE RISCO dA FASE 1 NOS 3 CENÁRIOS. 36

TABELA 4 - CÁlCULO do Volume de Venda dA FASE 1.

TABELA 5 - CÁlCULO dO Volume DE VENDAS DA FASE 2.

TABELA 6 - VALORES dOS FATORES DE RECEITA dA FASE 1 EM CADA CENÁRIO. 38

TABELA 7 - VALORES dOS FATORES DE RECEITA DA FASE 2 EM CADA CENÁRIO.

TABELA 8 - COMPARATIVOS DOS VPL'S 42 


\section{INTRODUÇÃO}

No final de 2019 o mercado imobiliário do Rio de Janeiro começou a apresentar uma recuperação em relação aos anos anteriores, segundo Associação de Dirigentes de Empresas do Mercado Imobiliário do Rio de Janeiro (Ademi-Rio). Os dados divulgados pelo estudo da SECOVIRIO em Panorama do Mercado imobiliário de 2019 aponta que o preço do $\mathrm{m}^{2}$ caiu 1,1\% de 2018 a 2019 e a oferta de vendas de apartamentos subiu 16\% no mesmo período. Com o advento da pandemia do Covid-19 em março de 2020, no entanto, a demanda voltou a retroceder em função da sensibilidade do mercado imobiliário às mudanças na economia e/ou na sociedade.

Essa sensibilidade é justificada pelo alto valor necessário para adquirir essa classe de ativos, pela oferta ou escassez de imóveis ofertados, custo elevado em caso de desistência da compra, além das características do produto, como localização, metragem, área de lazer, entre outros.

Quando se fala em compra de imóveis, não está se referindo a uma compra simples, por impulso, barata, mas sim, de um compra planejada, de alto valor e que atende uma expectativa sentimental, a realização de um sonho. Tudo que mexe com o emocional e de alto valor faz com que os consumidores reflitam com mais cautela sobre a tomada de decisão. Além disso, o mundo estava entrando em uma pandemia com uma grande incerteza de como a situação iria evoluir o que leva o consumidor a adiar investimentos e economizar reduzindo despesas.

Com isso, a expectativa anterior que era de um aumento da confiança entre construtoras e clientes e de crescimento na renda dos consumidores, não se concretizou por conta desse novo cenário em que a sociedade se viu inserida. Em março de 2020, o cenário de incertezas se formou, o que acarretou uma redução na intenção de compra de imóveis e na renegociação das dívidas, um aumento dos estoques e da inadimplência, e a paralização de novos lançamentos.

Com o passar dos meses, no entanto, mesmo com o cenário incerto, surgiu um alento inesperado para o mercado imobiliário: a queda na taxa básica de juros, a Selic, que fez com que as taxas de juros dos financiamentos caíssem para os menores níveis da história. Selic saiu de 6,50\% a.a. no início de 2019 para 4,50\% a.a. no final de 2019. Segundo o estudo realizado pela Câmara Brasileira da 
Indústria da Construção (CBIC, 2020) referente aos Indicadores Imobiliários Nacionais, houve um crescimento de vendas e de lançamentos a partir do início de 2021.

O mercado imobiliário vem sofrendo transformações para se adaptar as necessidades de seus clientes. Os perfis de alto poder aquisitivo, querem exclusividade em seu produto. Já os de menores poder aquisitivos desejam adquirir sua casa própria por um preço mais acessível.

Essas demandas acabaram levando o mercado da construção civil a se adaptar e tonar se mais flexível. Além dessa adequação, pode-se justificar que as construtoras começaram a olhar seus projetos com outros olhos. Será que há demanda para essa oferta que está sendo oferecida? Será que é necessário lançar o projeto inteiro? E se for um sucesso, é possível expandi-lo?

Olhando esses questionamentos, verifica-se que as incorporadoras podem realizar um projeto imobiliário de forma flexível para melhor adaptá-lo às necessidades do mercado. Dessa forma, uma incorporadora, por exemplo, pode escolher o melhor momento para lançar um projeto, o que representa uma opção de investir. Da mesma forma, pode optar por lança-lo em fases, onde o projeto é dividido em fases distintas que vão sendo lançadas e construídas de acordo com a demanda do projeto, o que pode ser modelado como uma opção de investir gradualmente. Outra alternativa é optar por expandir um projeto que foi executado com sucesso, que é uma opção de expansão, ou crescimento. Essa expansão pode ser realizada com a compra de um novo terreno.

Essas flexibilidades gerenciais são análogas a opções que a incorporadora possui para tomar decisões que maximizem o seu retorno em função de novas informações que serão recebidas do mercado no futuro. Dado que o valor dessas opções não pode ser determinado através dos métodos tradicionais de Fluxo de Caixa Descontado (FCD), é necessário recorrer a métodos de apreçamento de opções inicialmente desenvolvidos na década de 1970 por Black \& Scholes (1973) e Merton (1973).

Dessa forma, este trabalho analisa um empreendimento residencial hipotético localizado na Zona Oeste do Rio de Janeiro que será lançado em duas fases com o objetivo de determinar o momento ótimo de investir na segunda fase. $O$ empreendimento é um condomínio residencial com 9 blocos, contendo 788 unidades, entre elas 14 Lojas, 20 apartamentos térreos de 2 quartos, 12 
apartamentos térreos de 3 quartos, 492 apartamentos de 2 quartos, 144 de 3 quartos, 82 coberturas de 3 quartos e 24 coberturas de 4 quartos. A área comum é composta por piscina, sauna, salão gourmet, salão de festa, churrasqueira, academia e estacionamento. Por ser um projeto de grandes proporções, será analisado o seu lançamento em duas fases.

Tipicamente essa decisão é baseada na velocidade com que a fase inicial é vendida, o que é considerado uma indicação do futuro ritmo de vendas da fase seguinte. Analisamos esse projeto pela ótica das Opções Reais, considerando que a incorporadora possui uma opção de expansão com o objetivo de determinar o momento ideal para essa expansão. Os resultados indicam que a fase 2 do empreendimento deverá ser lançado no $18^{\circ}$ mês do projeto.

Este trabalho será divido da seguinte maneira: Após essa introdução, no capitulo 2 é feita uma revisão da literatura, e em seguida, no capitulo 3, é apresentada uma contextualização do mercado imobiliário. O capitulo 4 desenvolve o estudo de caso, que é o objeto desse trabalho e sua modelagem, e a seguir, no capitulo 5 são apresentados os resultados. Finalmente, no capitulo 6, são apresentadas as conclusões. 


\section{REVISÃO DA LITERATURA}

\subsection{OPÇÕES REAIS}

Quando se analisa um projeto não se pode desconsiderar as incertezas e as flexibilidades que estão embutidas no processo. A flexibilidade gerencial representa uma opção, ou oportunidade, que a empresa possui para exercer ou não uma escolha, que pode ser de investir, adiar, expandir, suspender, ou até abandonar um investimento.

As opções mais usadas são as Opções Financeiras e as Opções Reais. A primeira está vinculada a ativos negociados no mercado financeiro, como ações, títulos e comodities. Já opção real está vinculada a projetos tangíveis ou ativos reais, como imóveis, fábricas ou projetos de investimento. A figura 1 mostra as principais diferenças entre esses dois tipos de opções. O presente trabalho vai ter enfoque em Opções Reais, já que será avaliando a construção de um empreendimento residencial.

Opções Financeiras

Opção de Compra (Call)

Opção de Venda (Put)

Valor da Ação

Preço de Exercício

Volatilidade da Ação

Dividendos

\section{Opções Reais}

Opção de Investir/Expandir

Opção de Abandono

VP do Projeto

VP do Investimento

Volatilidade do Projeto

Fluxo de Caixa do Projeto

Figura 1 - Quadro comparativo entre Opções Financeiras e Opções Reais.

Fonte: Brandão (2002)

Ehrhardt e Brigham (2013) definem Opções Reais como

“...oportunidades para a administração mudar o prazo, o parâmetro e outros aspectos de um investimento em resposta às mudanças nas condições de mercado. Essas oportunidades são opções no sentido de que a administração 
pode, caso seja de interesse da empresa, realizar algumas ações; a administração não está obrigada a isso. Essas oportunidades são reais(...) porque envolvem decisões sobre o patrimônio real."

Logo, Opções Reais são os caminhos possíveis a serem escolhidos para ter mais êxito no resultado final do processo. Ou seja, são métodos de escolhas para alterar planos ou objetivos referentes a um investimento. Exemplos de opções reais podem ser:

- Adiar um investimento/projeto;

- Sair de um investimento/projeto;

- Rever um investimento/projeto;

Titmam (1985), classifica as opções reais em duas categorias: antes do início do projeto e depois do início do projeto. Na primeira categoria temos: a opções de investir gradualmente, opções de quando investir e opções operacionais. $\mathrm{Na}$ segunda temos a opões de crescimento, opções de parada temporária, opções de abandono e opções de substituição.

Opções de investir gradualmente, em estágio: Como o próprio nome diz, seria dividir o projeto em partes e analisar se continua ou não e em cada uma das etapas estabelecidas. Em vez de aplicar um alto investimento no projeto, dividi-lo em fase e ir analisando a utilização dos recursos gradativamente, de acordo com a resposta do mercado em relação ao projeto. Pode-se pensar no investimento inicial do projeto como o custo de uma opção de compra para investir na próxima etapa.

Opções de quando investir: São os tipos de opções mais usadas, pois as incertezas do presente podem ser sanadas no futuro, com isso, calcula-se quanto vale o custo de adiar a data da implementação de um investimento.

Opções operacionais: É mensurar como será estruturado o projeto, de maneira que ele se torne mais flexível às necessidades, às mudanças do mercado e da administração das organizações.

Opções de crescimento: As condições do mercado foram muito mais favoráveis do que o previsto, que faz necessário calcular a opção de expansão do projeto, escala ou escopo. Esse tipo de opção também é conhecido como Opção Estratégica, porque abre a possibilidade de programar novos projetos subsequentes.

Opções de parada temporária: Ao contrário do item anterior, se as condições do mercado forem menos favoráveis do que o previsto, o projeto pode 
ser interrompido e/ou retomada em um momento futuro. Isso traz flexibilidade ao projeto, já que se pode encerrá-lo durante um período ruim e retomá-lo em um momento bom.

Opções de abandono: A decisão de abandonar um projeto é ocasionada pelos prejuízos gerados ou na permanência dos maus resultados no futuro. Outra opção é a venda do projeto, que pode trazer muita mais lucratividade do que permanecer com o mesmo.

Opções de substituição: Pode ser substituição por produtos ou insumos, sendo que o primeiro traz uma flexibilidade na capacidade de alterar o mix de produto. Já o segundo, a substituição de insumos pode gerar a oportunidade de minimizar custos.

Além disso, as Opções Reais precisam atender três características para que a opção agregue valor ao projeto, são elas:

1) O investimento é parcialmente ou completamente irreversível: Independente do resultado do projeto, o capital investido não pode ser recuperado.

2) Existem incertezas acerca das futuras recompensas pelo investimento: Em outras palavras os Fluxos de Caixas são incertos. As incertezas são os pontos principais de risco do projeto.

3) Existe algum grau de flexibilidade no projeto: Os fluxos de caixas podem ser alterados à medida que decisões gerenciais são tomadas ao decorrer do tempo.

Com isso, percebe-se que o valor da opção está diretamente proporcional aos níveis de incertezas e flexibilidade. Quanto maior a incerteza e a flexibilidade maior será o valor da opção. A Figura 2 ilustra essa relação:

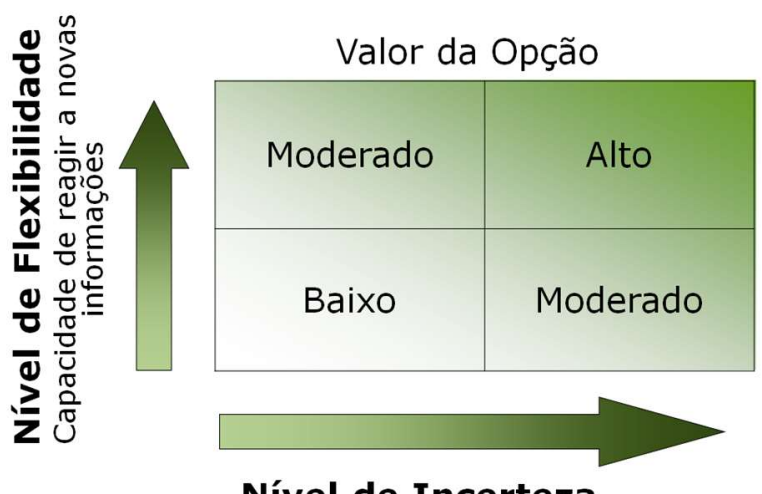

Figura 2 - Gráfico do Valor da Opção

Fonte: Copeland e Antikarov (2001) 


\subsubsection{MÉTODOS DE AVALIAÇÃO DE OPÇÕES REAIS}

A avaliação mais utilizada para analisar um projeto é o Fluxo de Caixa Descontado, FCD, que tem como metodologia descontar os fluxos gerados pelo projeto até o instante inicial, gerando um Valor Presente Líquido, VPL. O objetivo do método é saber, de forma simples, se o projeto terá lucro ou prejuízo. Para isso, basta saber se o VPL é positivo ou negativo, se for maior do que zero é provável que dê lucro, se for menor que zero tende a dar prejuízo. Mas esse método não consegue refletir o mercado de forma mais assertiva, pois ele não consegue explicar o valor da flexibilidade gerencial inerente a muitos tipos de projeto (Brandão, 2005).

Para incluir nos modelos as incertezas presentes no ambiente de mercado, os métodos de Opções Reais são mais adequados. Visando isso, nesse capítulo apresentaremos os dois métodos mais utilizados para precificação de Opções Reais: Tempo Contínuo e Discreto.

\subsubsection{MÉTODOS DE TEMPO CONTÍNUO: BLACK \& SCHOLES}

O modelo de Black \& Scholes (Black \& Scholes, 1973; Merton, 1973) foi criado por Fischer Black, Myron Scholes e Robert Merton em 1973 com objetivo de determinar o preço justo das ações de compra em função de variáveis conhecidas e observáveis no mercado.

Esse modelo segue algumas premissas:

1. As variações de preço respeitam uma distribuição normal;

2. A volatilidade do mercado se mantém constante ao longo do tempo;

3. Aplicável apenas para opções Europeias, que só podem ser exercidas no vencimento;

4. O preço segue um Movimento Browniano Geométrico (MGB);

Esse modelo, no entanto, tende a ser pouco aplicado em Opções Reais, onde a maioria das opções encontradas são do tipo Americanas, que podem ser exercidas em qualquer momento até o seu vencimento. Nos casos onde a opção é do tipo Europeia e o ativo subjacente segue um MGB, o uso desse método é aconselhável, já que, Black \& Scholes é simples de ser calculado em relação aos demais modelos 
de tempos contínuos, pois possui uma solução analítica de fácil aplicação, conhecida como a equação de Black \& Scholes:

$$
C(S, t)=S N\left(d_{1}\right)-K e^{-r(T-t)} N\left(d_{2}\right)
$$

onde

$$
\begin{aligned}
& d_{1}=\frac{\ln (S / K)+\left(r+\sigma^{2} / 2\right)(T-t)}{\sigma \sqrt{T-t}} \\
& d_{2}=d_{1}-\sigma \sqrt{T-t}
\end{aligned}
$$

- $\quad N($.$) é a área abaixo da curva normal$

- $\quad S$ é o preço da ação;

- $K$ é o preço de exercício da opção;

- $\quad r$ é a taxa de juros livre de risco anualizada, capitalizada continuamente;

- $\mu$ é a volatilidade da ação;

- $t$ é o tempo; geralmente usa-se $t=0$ e vencimento $=T$.

\subsubsection{MÉTODOS DISCRETOS: ÁRVORE BINOMIAL}

O modelo binomial é um método discreto que permite modelar inúmeras formas de derivativos e tipos de opções. É uma forma de modelar as incertezas, atribuindo valores e/ou probabilidades as duas possíveis opções que podem ser tomadas no processo com base na experiência do mercado. Esse modelo simplifica a realidade, porque no dia-a-dia sabe-se que tem mais do que duas opções de escolha. Essa estrutura forma uma figura que lembra uma árvore, com isso, tem o nome de Árvore Binomial. Na Figura 3 temos um exemplo de como fica essa estrutura. 


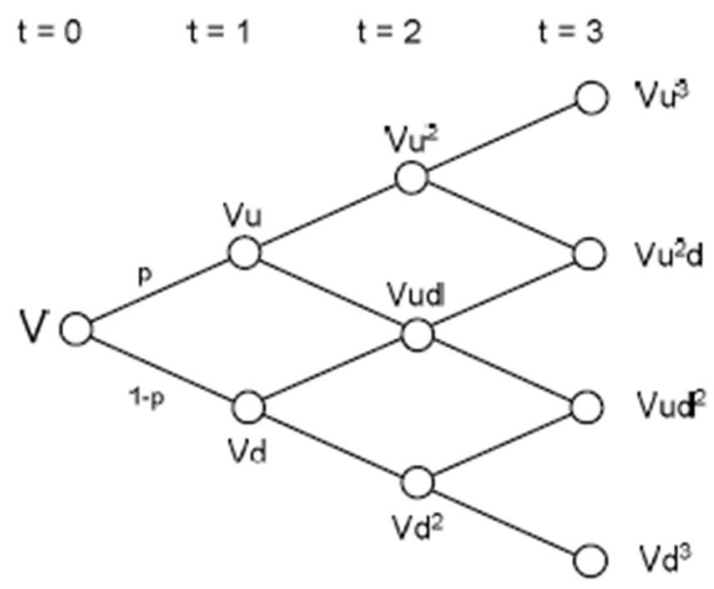

Figura 3 - Exemplo da estrutura de um Modelo binomial.

Fonte: Cox, Ross e Rubinstein (1979)

Além disso, o Modelo Binomial pode tornar-se um modelo contínuo de acordo com a complexidade que é dada ao processo. Caso a quantidade de períodos seja grande o suficiente, faz com que a diferença entre os períodos seja infinitamente pequena, passando-se a ter infinitos resultados, transformando o modelo discreto para contínuo.

O modelo binomial (Cox, Ross, \& Rubinstein, 1979) no limite se aproxima do modelo continuo do Movimento Geométrico Browniano. Embora não tenha a mesma precisão dos modelos contínuos, por ser um processo discreto de simples aplicação, é bastante utilizado em Opções Reais, onde não se exige a mesma precisão que é necessária para o cálculo de opções no mercado financeiras.

Segundo Dixit \& Pindyck (1994), MGB é utilizado para modelar ações, taxa de juros, preço de produtos e outras variáveis financeiras e econômicas. MGB é um processo estocástico, que ajuda a modelar preços de ativos levando a uma distribuição normal.

O modelo binomial é estruturado da seguinte forma: tem-se o preço do ativo, que é chamando de $S$, e esse valor pode caminhar para as duas opções distribuídas pelas suas probabilidades, $p$ e 1-p, sendo que a soma dessas duas probabilidades é 1. O preço $(\boldsymbol{S})$ é multiplicado por uma variável aleatória que são parâmetros de subida e descida, respetivamente, $\boldsymbol{u}$ e $\boldsymbol{d}$, sendo que $u>1$ e $d<1$.

$$
u=e^{\sigma \sqrt{\Delta t}} \quad d=\frac{1}{u}=e^{-\sigma \sqrt{\Delta t}} \quad p=\frac{(1+r)-d}{u-d}
$$


Sendo:

- $p$-Probabilidade;

- $\quad u$ - Parâmetro de subida;

- $\quad d$ - Parâmetro de descida;

- $\quad \sigma$-Volatilidade (desvio-padrão);

- $r$ - Taxa de juros livre de risco.

O que CRR demonstraram foi que os resultados dos preços resultem em uma distribuição log normal em que a média e a variância são conhecidas de acordo com o MGB.

\subsection{OPÇÕES REAIS NO MERCADO IMOBILIÁRIO}

O primeiro trabalho de opções reais aplicadas ao mercado imobiliário surgiu a apenas 35 anos atrás, numa modelagem realizada por Titman (1985). Esse estudo, feito em Los Angeles, EUA, analisou o valor de postergar os investimentos imobiliários considerando a influência econômicas e políticas monetárias governamentais. $\mathrm{O}$ autor demonstrou que pode ser valioso manter um terreno vazio em função da possibilidade de aumento do seu valor no futuro. Já Williams (1991) apresenta uma opção de abandono, incluindo modelo de incertezas, preço e custo por metro quadrado, obtendo resultados similares aos de Titman (1985). O seu estudo, porém, analisa uma opção de abandono como uma alternativa de desenvolvimento do terreno. O modelo encontra o momento ótimo para o abandono e os valores de mercado resultantes das propriedades desenvolvidas e não desenvolvidas.

Quigg (1993) estudou os preços dos terrenos em Seattle, EUA, e avaliou um modelo de opção de espera para investir, colocando em prática as inferências de Titman (1985) e complementando o modelo de tempo continuo de Willians (1991). O trabalho constatou que há um prêmio pela espera do investimento comprando a precificação das opções reais e o valor de venda dos imóveis.

Esses primeiros trabalhos foram mais práticos. Cappozza e Li (1994) desenvolveram um modelo mais teórico, analisando as opções de investir e suas interações e mostraram como o valor de projetos comerciais e residenciais interagem com a intensidade de capital e a densidade do projeto. 
Grenadier (1996) inovou agregando o conceito de jogos nas opções associando o tempo de investimento como estratégia para aumentar ou diminuir o andamento dos projetos. Além disso, exemplifica como o mercado imobiliário se comporta em cenários teoricamente contraditórios, como aumento das vendas mesmo com uma demanda reprimida e preço desvalorizados. Algum tempo depois, Cauley e Pavlov (2002), modelaram uma opção de espera de venda associado com valor dos imóveis e a dívida da hipoteca, em um nicho do mercado em Los Angeles. Eles concluíram que a construtora que possui pouco ou quase nenhum patrimônio por conta da sua dívida hipotecária, o valor de espera para vender o imóvel pode superar o valor líquido da dívida.

No Brasil, podemos destacar o trabalho de Medeiros (2008) que utilizou a teoria das opções reais para determinar o momento ótimo de iniciar a construção com a quantidade de unidades inseridas em um projeto residencial no Rio de Janeiro. Para isso se baseou do modelo de Willians (1991) e aprimorou o modelo incluindo o efeito dos impostos e tempo de construção. Conclui-se que o modelo refletia a realidade proposta no estudo.

Bernardi e Hochheim (2002), determinam a previsão da receita de venda através da simulação de Monte Carlo utilizando como base a velocidade de vendas, que é o comportamento da comercialização de imóveis. O cálculo da velocidade foi feito pela divisão da quantidade vendida e a quantidade em estoque.

Ribeiro (2004) aborda que teoria das opções reais vem para completar o método do Fluxo de Caixa Descontado, pois ele trata das incertezas e flexibilidades de um ativo. Com isso, ele apresenta algumas flexibilidades existentes em projetos de incorporação imobiliária, além de calcula-las de forma simples e intuitiva pelo método de quatro etapas de Copeland e Antikarov (2001).

Barbosa (2005) analisa a viabilidade econômica de um empreendimento imobiliário na cidade do Rio de Janeiro sob ótica das opções reais, considerando as opções de adiamento e abandono do projeto. Concluiu-se que inserir as estratégias de opções no FCD, a exposição ao risco cai em 50\%.

Fortunato et al. (2008), abordaram o valor da opção de abandono em lançamentos imobiliários residências no Rio de janeiro, em cima de comportamento dos consumidores no qual desistiam da compra feita para comprar mais para frente há um preço melhor. Essa manobrada era possível a partir da jurusprudência de que o comprador tem o direito a receber quase a totalidade dos valores antecipados. Os 
autores concluiram que o valor da opção de abandono é significativo, trazendo ganho para o comprador, perda para construtora e que em épocas de queda no valor dos imóveis, aumenta o risco de inadimplência nos incorporadores em função da redução na demanda do mercado e dos pagamentos a serem feitos para os consumidores que optaram por abandonar os imóveis comprados.

Outro trabalho que explora opções reais e mercado imobiliário é Almeida et al. (2019) no qual foi desenvolvido um modelo de jogos de opçoes reais. Os autores se basearam na metodologia de Grenadier (2002) e concluiram que quanto maior a quantidade de concorrentes, menor é o nivel de exigência do consumidor .

Num trabalho mais próximo deste, Rocha (2006) propõe uma análise estratégicas de investimento do setor de incorporação imobiliária e discute o tradeoff entre dois tipos de estratégias: lançamentos simultâneos e sequenciais. O primeiro requer um menor custo, mas uma maior incerteza nos resultados. $\mathrm{O}$ segundo foi associado a opção de adquirir informação, adiamento ou abandono do projeto. Para exemplificar o estudo, foi utilizado um caso de como um projeto por incorporação situado na cidade do Rio de Janeiro seria afetado pelas duas estratégias tendo velocidade de vendas distintas para cada etapa da construção. Esses trabalhos mostram a variedade de como pode-se interagir opções reais ao mercado imobiliário, já que esse universo é rico de incertezas e flexibilidades. 


\section{CONTEXTUALIZACAO}

\subsection{O MERCADO IMOBILIÁRIO}

O mercado imobiliário é o mercado de imóveis, que também pode ser visto como compra e venda de terrenos vazios ou propriedades construídas, como casas, prédios, lojas e qualquer outro tipo de estrutura.

Bapstistela (2005), define mercado imobiliário como:

"O mercado pode ser definido como o local onde são efetuadas transações comerciais envolvendo troca de bens, tangíveis ou intangíveis, ou direitos sobre os mesmos. Aqui o termo mercado refere-se àquele de concorrência perfeita, contendo em geral as seguintes características: Todos os que participam o fazem voluntariamente, e têm conhecimento pleno das condições vigentes, nenhum participante sozinho, é capaz de alterar as condições estabelecidas, cada transação é feita de maneira independente das demais"

Já Matos e Bartiw (2013) definem o setor da construção civil como fomento da economia como a criação de empregos.

"Esse setor proporciona uma renda urbana significativa, visualizada na abertura de novos empreendimentos habitacionais e comerciais, como edificios habitacionais, casas, centros comerciais, atacadistas, varejistas, bancos, salas comerciais, farmácias, padarias, supermercados, materiais de construção, enfim a existência de diversos setores localizados nos municípios, bairros e regiões metropolitanas",

Essas mesmas autoras citam quem são os agentes que compõem esse mercado:

"Esse mercado também é composto pelos seguintes agentes: imobiliárias, corretoras de imóveis autônomas, o profissional corretor, proprietário, empreiteiras de mão de 
obra, empresas da construção civil e empresas prestadoras de serviços em propaganda e marketing, que atuam nas atividades de administração e comercialização dos empreendimentos imobiliários"

Para Ball (1996), a construção habitacional vem representando um indicador relevante no crescimento urbano, não representa sozinho o crescimento da urbanização, mas é responsável por uma parcela significativa nas mudanças econômicas da população. Já que, essa demanda impulsiona a procura de outros serviços.

O mercado imobiliário teve o seu início no Brasil através das negociações de imóveis e terrenos no período da colonização. Não era um mercado formal, mas observa-se que a ideia de troca de terreno/imóvel por dinheiro ou outra propriedade já existia. Com o surgimento das cidades, a migração da população da zona rural para zona urbana foi estimulada para gerar movimento econômico nos centros urbanos. Com isso, a procura por casas ou terrenos para construir suas propriedades foi um processo natural e que caracterizou o início do mercado imobiliário.

Somente no início do século XX surgiram sindicatos regionais que se reuniram para promover medidas no sentido regulamentar os profissionais do mercado imobiliário, os corretores. Em 1962 surgiu o CRECI, Conselho Regional de Corretores de Imóveis, pela Lei 4.116, artigo 9:

"A fiscalização do exercício da profissão de Corretor de Imóveis será feita pelo Conselho Federal e pelos Conselhos Regionais de Corretores de Imóveis, que ficam criados por esta lei."

Em 1964 foi criada a Lei 4.380 que regulamentou o mercado imobiliário com a criação do Sistema Financeiro de Habitação (SFH), do Banco Nacional de Habitação (BNH) e das Sociedades de Créditos Imobiliários (SCI). Quatro anos depois é regulamentado o uso dos recursos das cadernetas de poupança. Em 1968 foi regulamentado que o recurso das cadernetas de poupança iriam ser a principal fonte de crédito para o financiamento imobiliário junto com o FGTS (Fundo de Garantia por Tempo de Serviço).

O Sistema de Financiamento Imobiliário (SFI) foi criado pela Lei 9.514/97, tirando a dependência dos recursos da caderneta de poupança e o FGTS. Na década 
seguinte foi criada a Cédula de Crédito Imobiliário (CCI) e as Letras de Crédito Imobiliário (LCI) com o objetivo de estimular esse mercado.

Portanto, esse mercado é muito sensível às questões sócios-econômicas, tanto para variações positivas quanto negativas. Quando a economia do país cresce, há geração de novos empregos, aumento da renda e estímulo para as pessoas comprarem mais e investir em uma casa própria. A mesma dinâmica acontece quando há uma queda na economia, com o consequente aumento do desemprego, redução da renda dos consumidores que passam a destinar os seus recursos para as suas necessidades imediatas de sustento. Logo, o desejo de ter um imóvel próprio deixa de ser viável e é adiado.

O mercado imobiliário do Rio de Janeiro também é afetado por esses fatores. No início de 2010, o metro quadrado da cidade era um dos mais caro do Brasil. Esse quadro se deu por conta de alguns fatores específicos que aconteciam na cidade, como a indicação do Brasil para sediar a Copa do Mundo de 2014 e fato do Rio de Janeiro ter sido escolhido para sediar os Jogos Olímpicos de 2016, além da diminuição da violência por contas das Unidades de Polícia Pacificadoras (UPP) e a expansão do crédito, entre outros. Com essas expectativas, a cidade tornou-se um polo de investimentos e quase todos os setores foram atingidos, como transporte urbano, criação e revitalização de polos esportivos, crescimento na rede hoteleira e nas construções civis.

Já nos meados dessa década o cenário era bem diferente, pois a economia começava a dar sinais de desaquecimento, a inflação começou a crescer e o número de desempregados aumentou. Os jogos olímpicos e Copa do Mundo, por sua vez, não trouxeram o legado esperado. Além disso, a taxa de juros para financiamento de imóveis teve um aumento por conta da grande retirada da caderneta de poupança, já que é uma das suas principais fontes de fornecimento de crédito, portanto, com poucos recursos para oferecer maior fica a taxa de juros. No final da década, já se passou a ver uma melhora, e o mercado tornou-se mais otimista. Um dos fatores que gerou esse movimento foi a baixa drástica das taxas de juros dos financiamentos de imóveis em função da queda da inflação. A Caixa Econômica Federal (CEF) trocou o indexador usado na correção monetária dos financiamentos para o IPCA (Índice Nacional de Preços ao Consumidor Amplo) ou TR (Taxa Referencial), porém, ambas vêm com histórico de índice zerado ou muito baixo, tornando o crédito quase sem correção monetária. 
A Figura 4 mostra que nos anos de 2019 e 2020 a TR fica nula e IPCA menor que o IGP-M (Índice Geral de Preços - Mercado) e INCC (Índice Nacional da Construção Civil). Logo, a mudança realizada pela CEF beneficiou os consumidores, já que esses índices estão em queda e o IGP-M e INCC em tendência de alta.

\section{ACUMULADO EM 12 MESES}

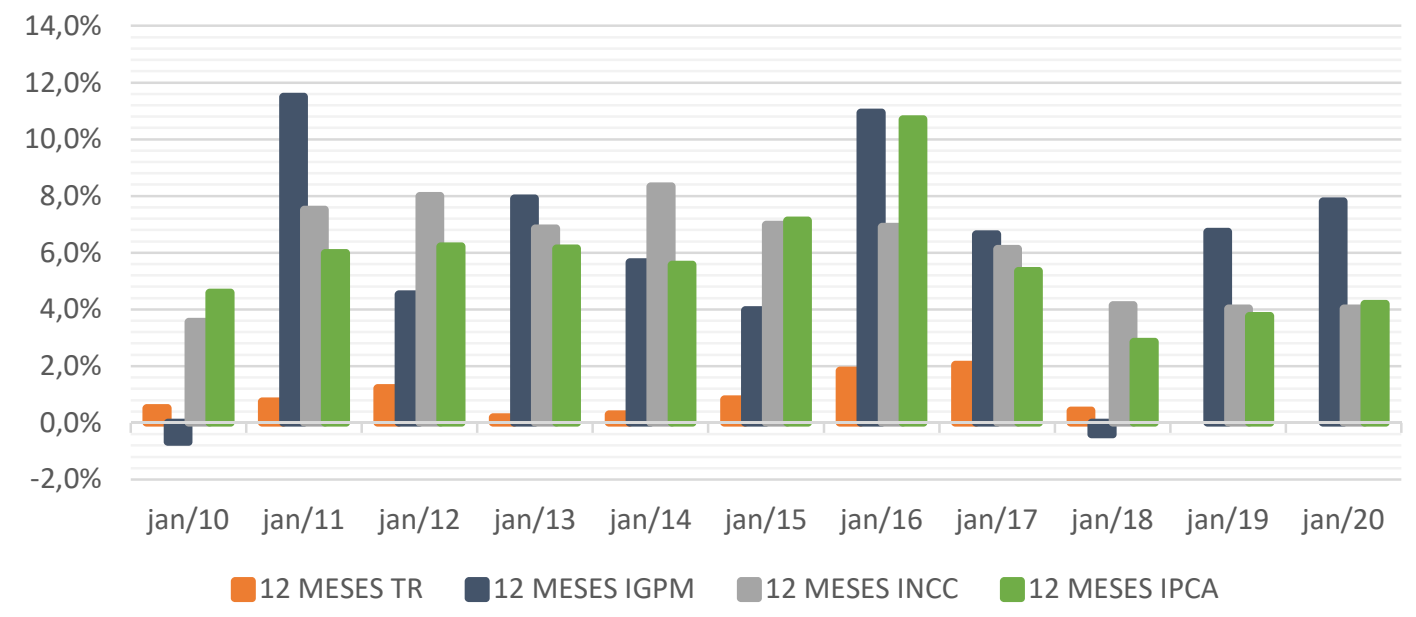

Figura 4 - Evolução dos principais índices utilizados no mercado imobiliário. Elaboração própria

Com isso os consumidores voltaram a ver o mercado imobiliário como uma forma de investimento. Segundo o Sindicato das Empresas de Compra, Venda, Locação e Administração de Imóveis e dos Condomínios Residenciais e Comerciais em todo o Estado do Rio de Janeiro, SECOVICRIO, na divulgação da Revista Cenário de 2020, pode-se concluir que, mesmo com a pandemia COVID-19, a quantidade de imóveis negociados da cidade do Rio de Janeiro caminha para terminar o ano melhor do que começou. A Figura 5 mostra o número de negociações no ano de 2020. 


\section{NEGOCIAÇÕES RESIDENCIAIS}

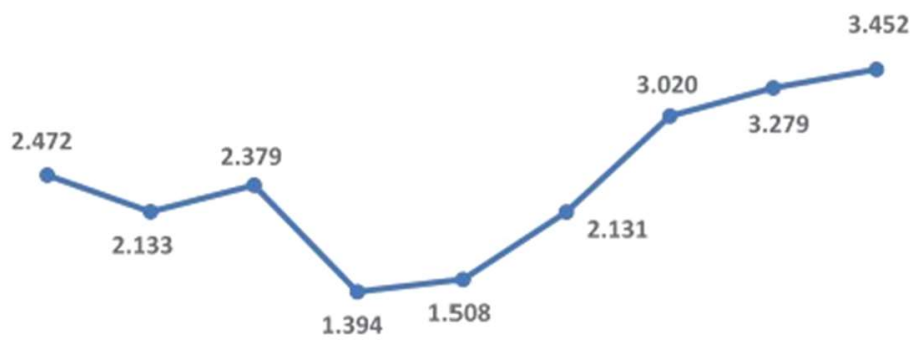

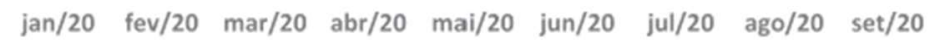

Fonte: Prefeitura do Rio de Janeiro

Figura 5 - Imóveis negociados na cidade do Rio de Janeiro.

Fonte: Revista Cenário

Na apresentação da coletiva de imprensa da CBIC, Câmara Brasileira da Indústria da Construção, referente ao terceiro trimestre de 2020, as vendas de unidades residências tiveram um aumento de $23,7 \%$ em relação ao $3^{\circ}$ trimestre de 2019 em relação ao $3^{\circ}$ trimestre de 2020. Considerando apenas a variação de um trimestre para outro, do $2^{\circ}$ trimestre de 2020 para o $3^{\circ}$ trimestre de 2020 , houve um aumento de $57,5 \%$, conforme mostra a Figura 6.

\section{Unidades residenciais vendidas $3^{\circ}$ Trimestre / $3 T 2020$}

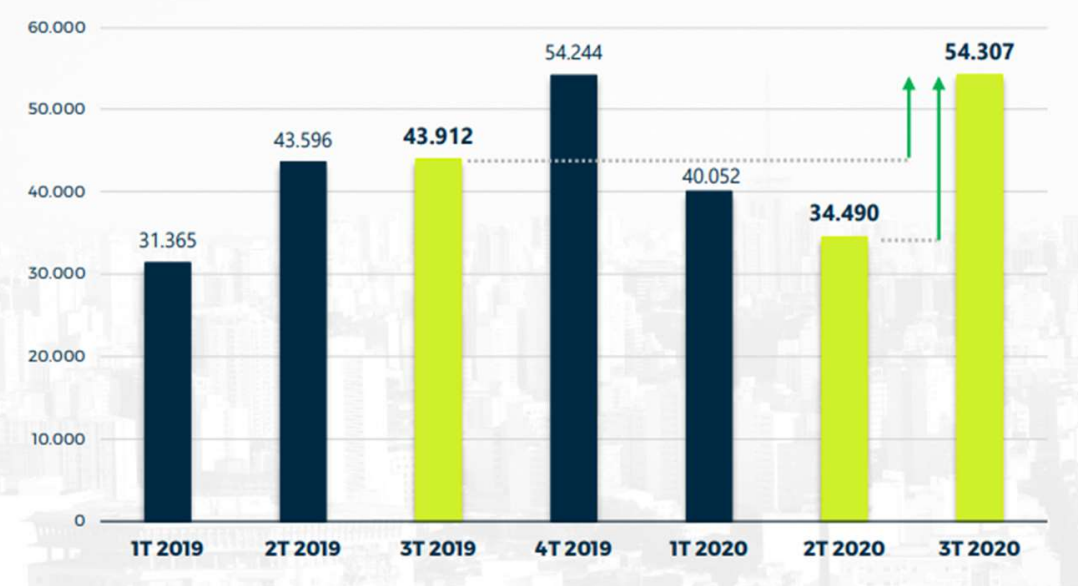

3T 2020: 54.307

2T 2020: 34.490

Crescimento de $\mathbf{5 7 , 5 \%} \Delta$

3T 2020: 54.307

3T 2019: 43.912

Crescimento de $\mathbf{2 3}, \mathbf{7} \% \Delta$

Média dos últimos

4 trimestres:

$\mathbf{4 5 . 7 7 3}$ unidades

Indicadores Imobiliários Nacionais $3 T 2020$

Figura 6 - Vendas de Unidades Residenciais de 2019 e 2020

Fonte: CBIC 
Isso mostra que os consumidores estão mais dispostos a adquirem esse tipo de produto. Pode-se citar alguns motivos para esse crescimento: a dupla utilidade dos imóveis, estabilidade da moradia ou geração de renda (aluguel); as baixas taxas de financiamento imobiliário; e aumento da inflação, como por exemplo, o acumulado dos últimos 12 meses do IGP-M está em aproximadamente em 23\% a.a. e no mesmo período do ano passado estava em quase 4\% a.a. Já a Selic está com o acumulado dos últimos 12 meses 2,60\% a.a. esse ano, e no mesmo período do ano passado, estava em 5,91\% a.a. A Figura 7 mostra a amplitude entre os principais índices do mercado imobiliário junto a Selic nos últimos anos.

\section{Comparativo de Indíces - Últimos 3 anos}

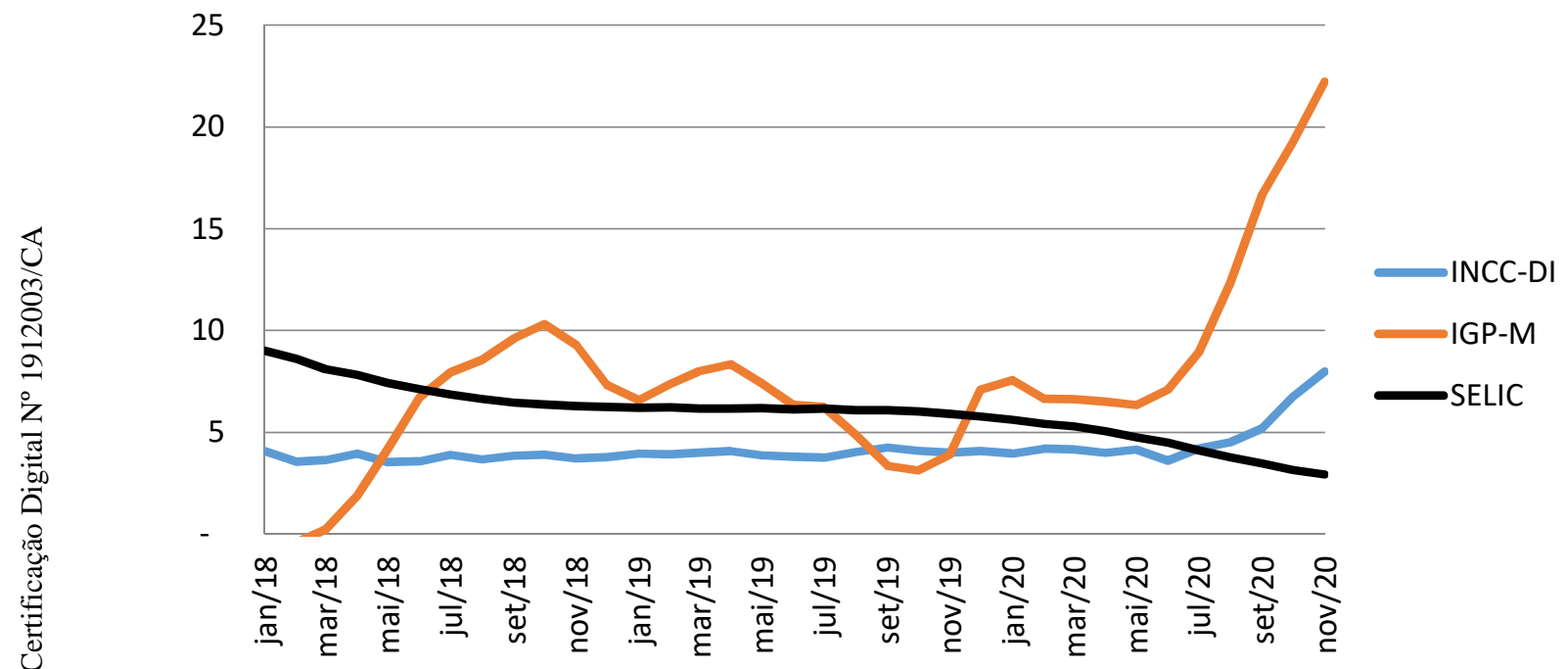

Figura 7 - Evolução dos últimos 12 meses dos Principais Índices do Mercado Imobiliário Elaboração própria

Outro ponto que o estudo da CBIC apontou foi o crescimento de unidades residenciais lançado nesse período de pandemia. Houve uma queda em relação ao terceiro trimestre de 2019 e ao de 2020, 10,5\%, mas há uma alta relevante entre o segundo trimestre e ao terceiro trimestre de 2020, 114,1\%, conforme ilustrado na Figura 8. 


\section{Unidades residenciais lançadas \\ $3^{\circ}$ Trimestre / 3 T 2020}

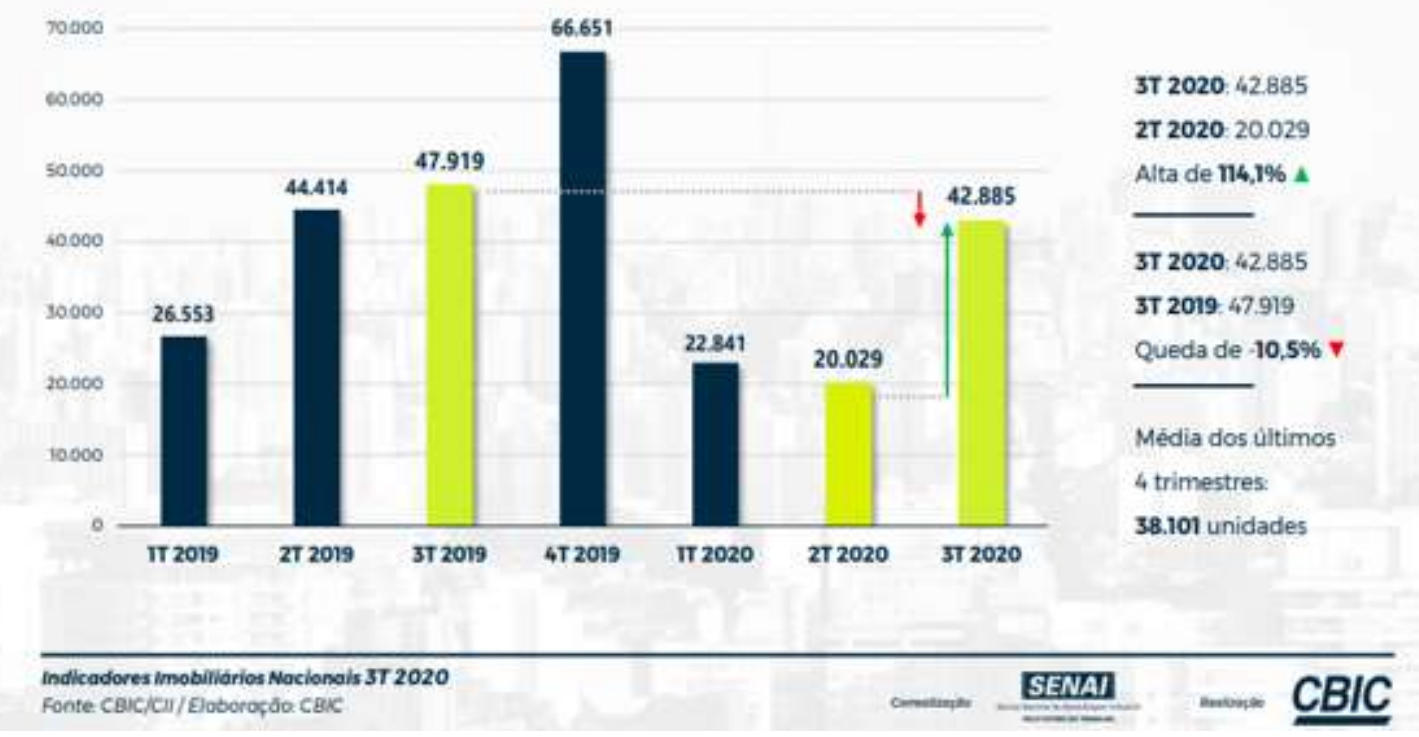

Figura 8 - Lançamento de Unidades Residências de 2019 e 2020

Fonte: $\mathrm{CBIC}$

Cruzando as duas informações, podemos concluir que o mercado está em uma tendência de crescimento conforme Figura 9.

\section{Comparativo entre Lançamento x Vendas}

Unidades residenciais lançadas e vendidas | acumulado 12 meses

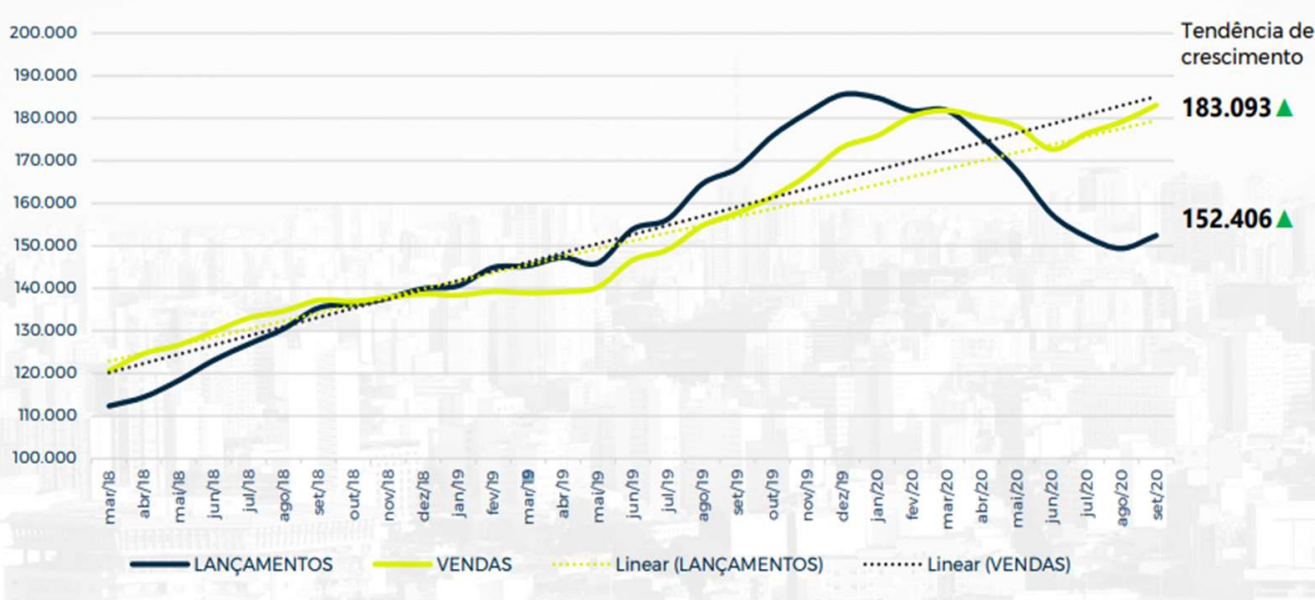

Indicadores Imobiliários Nacionais $3 T 2020$

Fonte: CBIC/CII/ Elaboração: CBIC

Figura 9 - Comparativo entre Unidades Lançadas e Vendidas Fonte: $\mathrm{CBIC}$ 
Visualizando esse novo cenário, pode-se se perceber que a economia vive altos e baixos, e isso leva os gestores do mercado imobiliário começarem a repensar quando seria a melhor hora de iniciar um novo projeto. 


\section{ESTUDO DE CASO}

Neste trabalho será analisado um caso de um condomínio residencial na zona oeste do Rio de Janeiro a ser construído pela construtora ABC Empreendimentos Imobiliários LTDA. O presente estudo analisará a viabilidade econômica do lançamento desse projeto em duas fases. Esse modelo poderá ser adaptado a outros projetos com características semelhantes.

A estruturação do processo de construção de um empreendimento imobiliário, pode ser dividido em 5 (cinco) macro etapas:

1. Compra do terreno, que pode ser em dinheiro ou permuta (troca do terreno por imóveis ou lojas que compõem o valor de venda);

2. Lançamento do empreendimento que, em média, tem a duração de seis meses;

3. Início da obra;

4. Construção;

5. Término da obra;

O presente estudo terá foco nas etapas 2 a 5. Supõem-se que o terreno já foi comprado à vista e que a sua compra não impacta na decisão de construir ou não.

O empreendimento consiste em um condomínio residencial composto por nove blocos com área de lazer comum a todos os prédios, composta por piscina, sauna, salão gourmet, salão de festa, churrasqueira, academia e estacionamento. Conforme dito no início desse trabalho, a estrutura do empreendimento Condomínio Residencial X será:

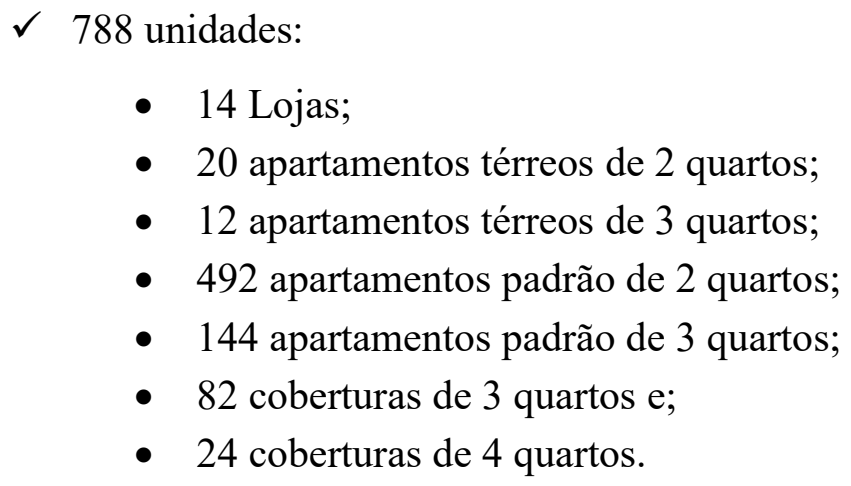

Consideramos que a construtora ABC Empreendimentos Imobiliários LTDA não deseja lançar o Condomínio Residencial X de uma única vez por ser muito 
grande e existirem muitas incertezas sobre a viabilidade do projeto completo. Assim, foi decido dividir o projeto em fases distintas e independentes para possível redução de risco do investimento.

Um dos principais objetivos das empresas é maximizar o seu lucro, e isso não poderia ser diferente com essa construtora em questão. Conseguir estimar possíveis perdas de lucro, torna mais efetivo o processo de decisão.

Nesse trabalho será levantado a hipótese de construir o projeto em 2 fases, sendo a primeira de imediato e a segunda em uma data futura a definir. Logo, esse estudo pretende estimar qual seria a melhor época para iniciar a fase 2 do projeto, consideramos que os primeiros 6 meses da fase 1 será destinado somente para essa fase. Logo a fase 2 só poderá ser iniciada no 7 mês. A fase 1 é composta pela venda e construção dos 4 primeiros blocos, que totalizam 348 unidades, e a fase 2 são os outros 5 blocos, que somam 440 unidades. A tabela 1 mostra como essa divisão foi feita por tipologias.

\begin{tabular}{|c|c|c|c|c|c|c|c|c|}
\hline $\begin{array}{l}\text { TIPOL } \\
\text { OGIAS }\end{array}$ & $\begin{array}{c}\text { APTO } 2 \\
\text { QUARTOS }\end{array}$ & $\begin{array}{c}\text { APTO } 3 \\
\text { QUARTOS }\end{array}$ & $\begin{array}{c}\text { COB } 3 \\
\text { QUARTOS }\end{array}$ & $\begin{array}{c}\text { COB } 4 \\
\text { QUARTOS }\end{array}$ & $\begin{array}{c}\text { GARDEN } \\
2 \text { QUARTOS }\end{array}$ & $\begin{array}{c}\text { GARDEN } \\
3 \text { QUARTOS }\end{array}$ & LOJA & TOTAL \\
\hline BLOCO 1 & 48 & 24 & 8 & 4 & - & - & 11 & 95 \\
\hline BLOCO 2 & 36 & 24 & 6 & 4 & 1 & 1 & 3 & 75 \\
\hline BLOCO 3 & 72 & - & 12 & - & 4 & 1 & - & 89 \\
\hline BLOCO 4 & 72 & - & 12 & - & 4 & 1 & - & 89 \\
\hline FASE 1 & 228 & 48 & 38 & 8 & 9 & 3 & 14 & 348 \\
\hline BLOCO 5 & 72 & - & 12 & - & 2 & 1 & - & 87 \\
\hline BLOCO 6 & 48 & 24 & 8 & 4 & 2 & 3 & - & 89 \\
\hline BLOCO 7 & 48 & 24 & 8 & 4 & 2 & 2 & - & 88 \\
\hline BLOCO 8 & 48 & 24 & 8 & 4 & 3 & 1 & - & 88 \\
\hline BLOCO 9 & 48 & 24 & 8 & 4 & 2 & 2 & - & 88 \\
\hline FASE 2 & 264 & 96 & 44 & 16 & 11 & 9 & 0 & 440 \\
\hline TOTAL & 492 & 144 & 82 & 24 & 20 & 12 & 14 & 788 \\
\hline
\end{tabular}

Esses tipos de projetos são influenciados por algumas variáveis econômicas, como a oferta e a demanda do mercado de onde está localizado o empreendimento, o preço do $\mathrm{m}^{2}$, o custo para viabilizar o projeto e a velocidade em que as vendas ocorrerão.

Para a presente análise, as variáveis do Condomínio Residencial X que serão destacadas são: a velocidade de venda e o preço do $\mathrm{m}^{2}$. Essas duas foram escolhidas porque influenciam diretamente na receita dos projetos e tem características especificas no qual podemos modelar e estimar possíveis cenários. 
As receitas são definidas pelo o valor de venda dos imóveis e quantas unidades vendidas em determinado período de tempo. Logo, isso mostra a grande importância de destacá-las no estudo. A velocidade de vendas foi estimada com base em seis lançamentos da construtora dos últimos 2 anos. Essa escolha foi feita, porque acredita-se que esses lançamentos podem refletir com mais veracidade o comportamento do mercado em um novo lançamento.

Para mitigar possíveis erros, consideraremos três cenários: pessimista, esperado e otimista. Para o Cenário Pessimista foi adotado o projeto mais longo, 16 meses; para o Cenário Esperado foi escolhido o projeto com o prazo intermediário dentre os últimos ocorridos, 10 períodos; e para o Cenário Otimista foi o de menor fluxo, 6 períodos. Portanto, têm-se três velocidades de vendas (pessimista, esperado e otimista). Na tabela 2 identifica-se a porcentagem adotada e o acumulado para cada um dos cenários.

\begin{tabular}{|c|c|c|}
\hline \multicolumn{3}{|c|}{ VELOCIDADE DE VENDA } \\
\hline $\begin{array}{l}\text { CENÁRIOS } \\
\text { PESSIMISTA }\end{array}$ & $\begin{array}{l}\text { CENÁRIOS } \\
\text { ESPERADO }\end{array}$ & $\begin{array}{l}\text { CENÁRIOS } \\
\text { OTIMISTA }\end{array}$ \\
\hline $18,79 \%$ & $23,45 \%$ & $29,57 \%$ \\
\hline $15,16 \%$ & $17,24 \%$ & $20,39 \%$ \\
\hline $13,08 \%$ & $16,55 \%$ & $19,13 \%$ \\
\hline $10,75 \%$ & $12,41 \%$ & $15,82 \%$ \\
\hline $8,34 \%$ & $14,48 \%$ & $9,74 \%$ \\
\hline $6,56 \%$ & $11,04 \%$ & $5,35 \%$ \\
\hline $4,20 \%$ & $2,76 \%$ & \\
\hline $3,00 \%$ & $0,69 \%$ & \\
\hline $2,30 \%$ & $0,69 \%$ & \\
\hline $2,73 \%$ & $0,69 \%$ & \\
\hline $2,73 \%$ & & \\
\hline $2,73 \%$ & & \\
\hline $2,73 \%$ & & \\
\hline $2,73 \%$ & & \\
\hline $2,73 \%$ & & \\
\hline $1,44 \%$ & & \\
\hline $100,00 \%$ & $100,00 \%$ & $100,00 \%$ \\
\hline
\end{tabular}

\begin{tabular}{|c|c|c|}
\hline \multicolumn{3}{|c|}{ VELOCIDADE DE VENDA ACUMULADO } \\
\hline $\begin{array}{l}\text { CENÁRIOS } \\
\text { PESSIMISTA }\end{array}$ & $\begin{array}{l}\text { CENÁRIOS } \\
\text { ESPERADO }\end{array}$ & $\begin{array}{l}\text { CENÁRIOS } \\
\text { OTIMISTA }\end{array}$ \\
\hline $18,79 \%$ & $23,45 \%$ & $29,57 \%$ \\
\hline $33,95 \%$ & $40,69 \%$ & $49,96 \%$ \\
\hline $47,03 \%$ & $57,24 \%$ & $69,09 \%$ \\
\hline $57,78 \%$ & $69,66 \%$ & $84,91 \%$ \\
\hline $66,12 \%$ & $84,14 \%$ & $94,65 \%$ \\
\hline $72,68 \%$ & $95,18 \%$ & $100,00 \%$ \\
\hline $76,88 \%$ & $97,93 \%$ & \\
\hline $79,88 \%$ & $98,62 \%$ & \\
\hline $82,18 \%$ & $99,31 \%$ & \\
\hline $84,91 \%$ & $100,00 \%$ & \\
\hline $87,64 \%$ & & \\
\hline $90,37 \%$ & & \\
\hline $93,10 \%$ & & \\
\hline $95,83 \%$ & & \\
\hline $98,56 \%$ & & \\
\hline $100,00 \%$ & & \\
\hline $100,00 \%$ & $100,00 \%$ & $100,00 \%$ \\
\hline
\end{tabular}

Elaboração própria.

Afim de comparar as velocidades de vendas acumuladas dos cenários escolhidos, foi elaborado o Figura 10, onde pode-se identificar como cada cenário se comporta ao longo do tempo. 
VELOCIDADE DE VENDA ACUMULADA

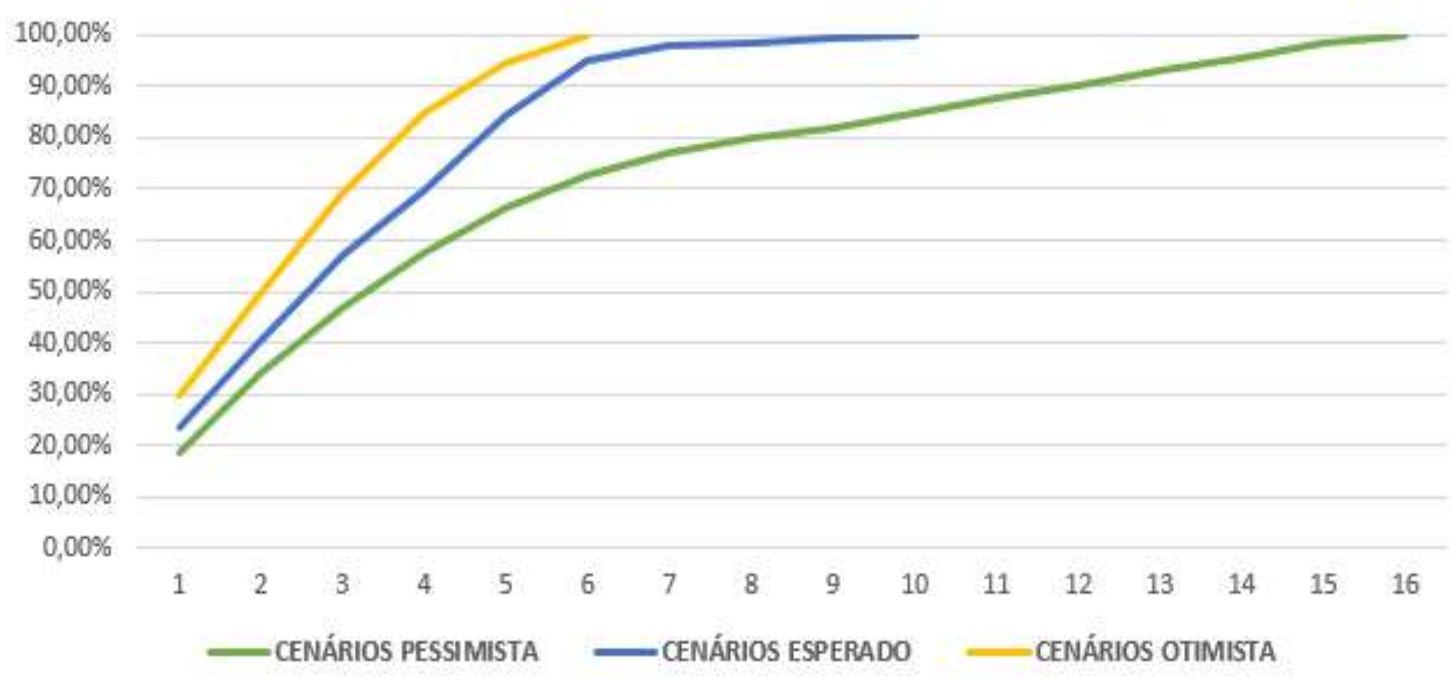

Figura 10 - Cenários analisados.

Elaboração própria

A segunda variável a ser destacada é o preço do $\mathrm{m}^{2}$, que será a variável de incerteza. Essa variável é a base do preço de venda dos imóveis, no qual influenciam diretamente a receita do projeto. O preço de venda é estocástico e segue um Movimento Geométrico Browniano (MGB). MGB é descrito pela Eq. (1), no qual $\alpha$ é a taxa crescimento esperada, $\sigma$ é a volatilidade do preço e $d z=\varepsilon \sqrt{ } d t$, aonde $\varepsilon \approx N(0,1)$ é o incremento de Wiener padrão.

$$
d S=\alpha S d t+\sigma S d z
$$

Para definir os elementos da Eq. (1), foi usada a série do índice FIPEZAP, divulgada pelo Zapimoveis desde Janeiro de 2008. Esse índice divulga o preço do $\mathrm{m}^{2}$ e a variação de um mês para o outro. A FIPEZAP é uma parceria entre a Fipe e o portal ZAP desde 2010. A base do índice são os preços de imóveis anunciados na plataforma do ZAP Imóveis. Segundo o próprio site, esse índice é o primeiro indicador a fazer um acompanhamento da evolução dos preços do mercado imobiliário brasileiro.

Esse índice divulga o preço médio do Brasil e de todos os estados referente a empreendimentos residências e comerciais. No entanto, foram utilizados somente os valores do preço médio dos imóveis residenciais do estado do Rio de Janeiro. Essa série vem em valores nominais, isso quer dizer que, sem desconsiderar a inflação. Para conseguir valores reais, foi deflacionado pelo INCC-DI, Índice 
Nacional da Construção Civil. Foi escolhido esse indicador porque, além de ser divulgado gratuitamente pelo Fundação Getúlio Vargas (FGV), é um dos mais usados no mercado imobiliário e seu cálculo é baseado nos valores dos materiais usados nas estruturas, instalação e acabamentos, equipamentos e mão de obra do país.

Foi considerado o período de janeiro de 2013 a fevereiro de 2021, dado que no período anterior a 2013 houve uma significativa valorização imobiliária no Rio de Janeiro que não se supõe que se repita nos próximos 24 meses, que é o período de lançamento e construção do empreendimento.

Com essa série deflacionada, foi calculada a volatilidade $(\sigma$, desvio-padrão da série), drift (a diferença do valor final e inicial da série, dividido pelo inicial, dividido pelo número de período menos 1), e os parâmetros do modelo binomial: $u$ (parâmetro de subida), $d$ (parâmetro de descida) e $p$ (probabilidade). Os valores encontrados foram:

- $\sigma=1,22 \%$ a.m.

- Drift $=0,079 \%$ a.m.

- $u=1,012$

- $d=0,987$

- $p=53 \%$

Para calcular o preço do $\mathrm{m}^{2}$ inicial $\left(P_{0}\right)$, foi feito uma média ponderada entre a quantidade de unidade de cada tipologia e os preços praticados no mercado. O valor obtido foi $\mathrm{R} \$ 6.855,93$, que foi utilizado como base para fazer a projeção de preços que poderiam ocorrer nos próximos meses.

A taxa livre de risco adotada foi de $4,00 \%$ a.a. $(0,33 \%$ a.m.). Esse valor foi adotado com base no relatório FOCUS - Distribuição de Frequência do Banco Central de fevereiro de 2021 quando a taxa Selic estava com 4,00\% a.a. A construtora $\mathrm{ABC}$ Empreendimentos Imobiliários LTDA utiliza uma taxa de retorno em seus projetos de $12,68 \%$ a.a., ou 1,00\% a.m.

A flexibilidade que a empresa tem para escolher o momento ótimo de expandir para a segunda fase do projeto é análoga a uma opção de investimento, e pode ser modelada como tal. Dado que a presença da opção altera o risco do projeto, para o seu apreçamento é necessário adotar a medida neutra a risco onde o fator de 
crescimento da variável incerta do ativo subjacente é ajustado e os fluxos de caixa são descontados à taxa livre de risco.

Quando se trata de um ativo de mercado analisado isoladamente a taxa de retorno $\mu$ é idêntica à apreciação $\alpha$ do ativo, e esse ajuste é feito simplesmente substituindo-se tanto a taxa de retorno ajustada ao risco $\mu$ quanto o drift pela taxa livre de risco $r$. No entanto, como o ativo subjacente que está sendo modelado é o preço por metro quadrado e não o valor do projeto em si, torna-se necessário fazer o ajuste no parâmetro de drift através da subtração do seu prêmio de risco.

$\mathrm{Na}$ ausência de opções, o valor do projeto determinado pelo valor presente do seu fluxo de caixa descontado à taxa de risco $\mu$ deve ser idêntico ao seu valor determinado pela avaliação neutra a risco. No presente estudo, foi adotado esse último método, onde o VPL do projeto neutro a risco, sem considerar eventuais interferências, deveria ser igual ao VPL do projeto original, ou seja, os fluxos não são iguais, mas seus VPL's sim. Com isso, foram criados dois fluxos de caixa da fase 1 em cada um dos cenários: original e neutro a risco. Nesse segundo, para calcular o prêmio de risco, foi utilizada uma ferramenta do Excel chamada "Atingir Meta”. Essa função determinar um valor a partir de uma equação pré-determinada e um valor especificado. No caso, a equação utilizada foi o VPL e o valor que deveria ser atingido era o VPL do fluxo original. A tabela 3 apresenta os valores de cada um dos prêmios de risco calculados. Uma discussão mais detalhada dessa metodologia pode ser encontrada em Freitas e Brandao (2010).

\begin{tabular}{|l|c|}
\hline Cenários & Prêmio de Risco \\
\hline Otimista & $-0,48 \%$ \\
\hline Esperado & $-0,46 \%$ \\
\hline Pessimista & $-0,43 \%$ \\
\hline
\end{tabular}

Tabela 3 - Prêmio de Risco da Fase 1 nos 3 cenários. Elaboração própria

Ao contrário do que esperado, o prêmio de risco ficou negativo, porque existe um alto custo a ser feito no último período aliado a abaixa taxa de crescimento do preço do $\mathrm{m}^{2}$.

A montagem do fluxo de caixa do projeto foi dividido em partes. A primeira foi calcular o volume de vendas de cada fase. $\mathrm{O}$ volume de vendas é diferente em cada uma delas, pois depende da área privativa e a quantidade de cada unidade por 
tipologias. Logo o cálculo foi feito conforme Eq. (2), sendo $n$ a tipologia que será calculada considerando que a quantidade de tipologias são 7 .

Volume de Vendas $=\sum_{n=1}^{7}$ Quantidade $_{n} \times$ Área Privativa $_{n}$

As tabelas 4 e 5 , referentes às fases 1 e 2 , respectivamente, apresentam as quantidades e as áreas privativas de cada tipologia, e os seus respectivos volumes de vendas com base na Eq. (2).

\begin{tabular}{|l|c|c|c|}
\hline \multicolumn{4}{|c|}{ VOLUME DE VENDAS FASE 1 } \\
UNIDADES TIPO & QUANTIDADE & $\begin{array}{c}\text { ÁREA } \\
\text { PRIVATIVA }\end{array}$ & $\begin{array}{c}\text { VOLUME DE } \\
\text { VENDA }\end{array}$ \\
\hline Lojas & 14 & 103,89 & $1.454,51$ \\
\hline Garden 2 quartos & 9 & 97,66 & 878,94 \\
\hline Garden 3 quartos & 3 & 122,85 & 368,55 \\
\hline Apto 2 quartos & 228 & 72,99 & $16.641,13$ \\
\hline Apto 3 quartos & 48 & 93,21 & $4.474,08$ \\
\hline Cobertura 3 quartos & 38 & 146,70 & $5.574,60$ \\
\hline Cobertura 4 quartos & 8 & 184,74 & $1.477,92$ \\
\hline \multicolumn{1}{r|}{ Total } & $\mathbf{3 4 8}$ & $\mathbf{8 2 2 , 0 4}$ & $\mathbf{3 0 . 8 6 9 , 7 3}$ \\
\hline
\end{tabular}

Tabela 4 - Cálculo do Volume de Venda da Fase 1.

Elaboração própria

\begin{tabular}{|l|c|c|c|}
\hline \multicolumn{4}{c}{ VOLUME DE VENDAS FASE 2 } \\
UNIDADES TIPO & QUANTIDADE & $\begin{array}{c}\text { ÁREA } \\
\text { PRIVATIVA }\end{array}$ & $\begin{array}{c}\text { VOLUME DE } \\
\text { VENDA }\end{array}$ \\
\hline Lojas & 0 & 103,89 & 0,00 \\
\hline Garden 2 quartos & 11 & 97,66 & $1.074,26$ \\
\hline Garden 3 quartos & 9 & 122,85 & $1.105,65$ \\
\hline Apto 2 quartos & 264 & 72,99 & $19.268,68$ \\
\hline Apto 3 quartos & 96 & 93,21 & $8.948,16$ \\
\hline Cobertura 3 quartos & 44 & 146,70 & $6.454,80$ \\
\hline Cobertura 4 quartos & 16 & 184,74 & $2.955,84$ \\
\hline \multicolumn{1}{r|}{ Total } & $\mathbf{4 4 0}$ & $\mathbf{8 2 2 , 0 4}$ & $\mathbf{3 9 . 8 0 7 , 3 9}$ \\
\hline
\end{tabular}

Tabela 5 - Cálculo do Volume de Vendas da Fase 2.

Elaboração própria

A partir desse volume de venda, foi criado um fator chamado de Fator Receita (Eq. (3)). Esse fator é baseado no produto do volume de venda e da velocidade de venda em relação ao tempo de cada fase e cenário.

Fator Receita $_{i}=$ Volume de Venda $_{i} \times$ Velocidade de Venda $_{i}$ 
A tabela 6 apresenta os valores do Fator Receita da fase 1 de acordo com o cada um dos três cenários propostos e o tempo $i$ (em meses). O cenário pessimista tem-se 16 fatores, no esperado tem 10 fatores e no otimista tem 6 fatores.

\begin{tabular}{|c|c|c|c|c|c|c|}
\hline \multirow{3}{*}{$\begin{array}{c}\text { TEMPO } \\
i\end{array}$} & \multicolumn{4}{|c|}{ VOLUME DE VENDAS FASE 1: } & & \\
\hline & \multicolumn{2}{|c|}{ CENÁRIOS PESSIMISTA } & \multicolumn{2}{|c|}{ CENÁRIOS ESPERADO } & \multicolumn{2}{|c|}{ CENÁRIOS OTIMISTA } \\
\hline & $\begin{array}{l}\text { VELOCIDADE } \\
\text { DE VENDAS }\end{array}$ & $\begin{array}{c}\text { FATOR } \\
\text { RECEITA }\end{array}$ & $\begin{array}{l}\text { VELOCIDADE } \\
\text { DE VENDAS }\end{array}$ & $\begin{array}{c}\text { FATOR } \\
\text { RECEITA }\end{array}$ & $\begin{array}{l}\text { VELOCIDADE } \\
\text { DE VENDAS }\end{array}$ & $\begin{array}{c}\text { FATOR } \\
\text { RECEITA }\end{array}$ \\
\hline 1 & $18,79 \%$ & $5.800,42$ & $23,45 \%$ & $7.238,42$ & $29,57 \%$ & $9.126,70$ \\
\hline 2 & $15,16 \%$ & $4.679,85$ & $17,24 \%$ & $5.322,37$ & $20,39 \%$ & $6.294,74$ \\
\hline 3 & $13,08 \%$ & $4.037,76$ & $16,55 \%$ & $5.109,47$ & $19,13 \%$ & $5.905,51$ \\
\hline 4 & $10,75 \%$ & $3.318,50$ & $12,41 \%$ & $3.832,10$ & $15,83 \%$ & $4.885,47$ \\
\hline 5 & $8,34 \%$ & $2.574,54$ & $14,48 \%$ & $4.469,94$ & $9,74 \%$ & $3.006,44$ \\
\hline 6 & $6,56 \%$ & $2.025,05$ & $11,04 \%$ & $3.408,02$ & $5,35 \%$ & $1.651,53$ \\
\hline 7 & $4,20 \%$ & $1.296,53$ & $2,76 \%$ & 851,58 & & \\
\hline 8 & $3,00 \%$ & 926,09 & $0,69 \%$ & 212,89 & & \\
\hline 9 & $2,30 \%$ & 710,00 & $0,69 \%$ & 212,89 & & \\
\hline 10 & $2,73 \%$ & 842,74 & $0,69 \%$ & 212,89 & & \\
\hline 11 & $2,73 \%$ & 842,74 & & & & \\
\hline 12 & $2,73 \%$ & 842,74 & & & & \\
\hline 13 & $2,73 \%$ & 842,74 & & & & \\
\hline 14 & $2,73 \%$ & 842,74 & & & & \\
\hline 15 & $2,73 \%$ & 842,74 & & & & \\
\hline 16 & $1,44 \%$ & 444,52 & & & & \\
\hline
\end{tabular}

Tabela 6 - Valores dos Fatores de Receita da Fase 1 em cada cenário.

Elaboração própria

A tabela 7 apresenta dados de velocidade de venda referentes à fase 2 do projeto. A importância desse fator se torna essencial para a montagem do fluxo de caixa. Como o preço do metro quadrado não é uma variável fixa, ela oscila de acordo com os parâmetros do binomial que foram expostos acima, a criação desse fator facilita o cálculo da receita. Com base nesses últimos itens pode-se chegar nas receitas dos fluxos de caixas conforme Eq. (4).

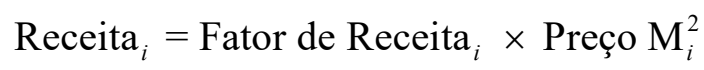




\begin{tabular}{|c|c|c|c|c|c|c|}
\hline \multirow{3}{*}{$\begin{array}{c}\text { TEMPO } \\
i\end{array}$} & \multicolumn{3}{|c|}{ VOLUME DE VENDAS FASE 2: } & $39.807,39$ & \multirow{2}{*}{\multicolumn{2}{|c|}{ CENÁRIOS OTIMISTA }} \\
\hline & \multicolumn{2}{|c|}{ CENÁRIOS PESSIMISTA } & \multicolumn{2}{|c|}{ CENÁRIOS ESPERADO } & & \\
\hline & $\begin{array}{l}\text { VELOCIDADE } \\
\text { DE VENDAS }\end{array}$ & $\begin{array}{c}\text { FATOR } \\
\text { RECEITA }\end{array}$ & $\begin{array}{l}\text { VELOCIDADE } \\
\text { DE VENDAS }\end{array}$ & $\begin{array}{c}\text { FATOR } \\
\text { RECEITA }\end{array}$ & $\begin{array}{l}\text { VELOCIDADE } \\
\text { DE VENDAS }\end{array}$ & $\begin{array}{c}\text { FATOR } \\
\text { RECEITA }\end{array}$ \\
\hline 1 & $18,79 \%$ & $7.479,81$ & $23,45 \%$ & $9.334,15$ & $29,57 \%$ & $11.769,14$ \\
\hline 2 & $15,16 \%$ & $6.034,80$ & $17,24 \%$ & $6.863,34$ & $20,39 \%$ & $8.117,25$ \\
\hline 3 & $13,08 \%$ & $5.206,81$ & $16,55 \%$ & $6.588,81$ & $19,13 \%$ & $7.615,33$ \\
\hline 4 & $10,75 \%$ & $4.279,29$ & $12,41 \%$ & $4.941,61$ & $15,83 \%$ & $6.299,95$ \\
\hline 5 & $8,34 \%$ & $3.319,94$ & $14,48 \%$ & $5.764,11$ & $9,74 \%$ & $3.876,89$ \\
\hline 6 & $6,56 \%$ & $2.611,36$ & $11,04 \%$ & $4.394,74$ & $5,35 \%$ & $2.129,70$ \\
\hline 7 & $4,20 \%$ & $1.671,91$ & $2,76 \%$ & $1.098,13$ & & \\
\hline 8 & $3,00 \%$ & $1.194,22$ & $0,69 \%$ & 274,53 & & \\
\hline 9 & $2,30 \%$ & 915,57 & $0,69 \%$ & 274,53 & & \\
\hline 10 & $2,73 \%$ & $1.086,74$ & $0,69 \%$ & 274,53 & & \\
\hline 11 & $2,73 \%$ & $1.086,74$ & & & & \\
\hline 12 & $2,73 \%$ & $1.086,74$ & & & & \\
\hline 13 & $2,73 \%$ & $1.086,74$ & & & & \\
\hline 14 & $2,73 \%$ & $1.086,74$ & & & & \\
\hline 15 & $2,73 \%$ & $1.086,74$ & & & & \\
\hline 16 & $1,44 \%$ & 573,23 & & & & \\
\hline
\end{tabular}

As despesas de cada fase desse projeto já foram pré-estabelecidas e que sofrem alguma alteração são os itens que dependem da receita, como a avaliação de crédito dos clientes, comissão de vendas e os impostos, os demais itens permanecem com o mesmo valor. Outro ponto a ser destacado nas despesas é descapitalização de seus valores que ocorrerão após o termino das vendas. Exemplo, no cenário pessimista, a velocidade de vendas vai até o $16^{\circ}$ mês, porém existem despesas que acontecerão após esse período. Para não prejudicar a análise e viabilizar a utilização do software DPL ${ }^{\mathrm{TM}}$ foi aplicada a Eq. (5) no último mês após o término das vendas: Os gastos que estão sendo consideradas nesse modelo são gastos de construção, terreno, marketings, despesas fixas, avaliação de crédito do cliente, custos complementares, comissão de vendas, impostos e outros.

$$
\text { Despesa }_{n}=\sum_{y=n+1}^{42} \frac{\text { Despesa }_{y}}{(1+i)^{y-1}}
$$

Com as informações descritas acima foi gerado os fluxos de caixas de cada fase e seus cenários. Totalizaram 6 fluxos de caixas, $F C_{F C}$, sendo $\mathrm{F}$ a fase e $\mathrm{Co}$ cenário, sendo exposto nos anexos 1 ao 6 , respectivamente: 
$\Rightarrow F C_{11}=$ Fluxo de Caixa da Fase 1 cenário Pessemista;

$\Rightarrow F C_{12}=$ Fluxo de Caixa da Fase 1 cenário Esperado;

$\Rightarrow F C_{13}=$ Fluxo de Caixa da Fase 1 cenário Otimista;

$\Rightarrow F C_{21}=$ Fluxo de Caixa da Fase 2 cenário Pessemista;

$\Rightarrow F C_{22}=$ Fluxo de Caixa da Fase 2 cenário Esperado;

$\Rightarrow F C_{23}=$ Fluxo de Caixa da Fase 2 cenário Otimista;

Os fluxos da fase 2 foram subdivididos em mais 12 fluxos para cada cenário. Esses fluxos foram desenhados para iniciar em momentos diferentes, sendo que o primeiro fluxo da fase 2 se inicia no mês 7 e o último fluxo, $12^{\circ}$, inicia no mês 18 . Esses fluxos foram montados com características iguais, como: o volume de vendas e as despesas. O que vai oscilar de um fluxo para o outro são os preços do $\mathrm{m}^{2}$ aplicado mês a mês. Como já dito anteriormente, essa variável segue MGB e é ela que modela o estudo. Com isso, o total das receitas se alteram e consequentemente o fluxo de caixa. Isso gera 12 VPL's diferentes em tempos diferentes. 


\section{RESULTADOS}

Com as bases dos fluxos montadas, o DPL foi modelado da seguinte forma: até o $6^{\circ}$ período ocorre somente a evolução do Preço por $\mathrm{m}^{2}$ através do método binomial. A partir do $7^{\circ}$ período foi incluído a decisão de lançar ou não a fase 2 . A figura 11 mostra a estrutura montada no qual o modelo foi aplicado.
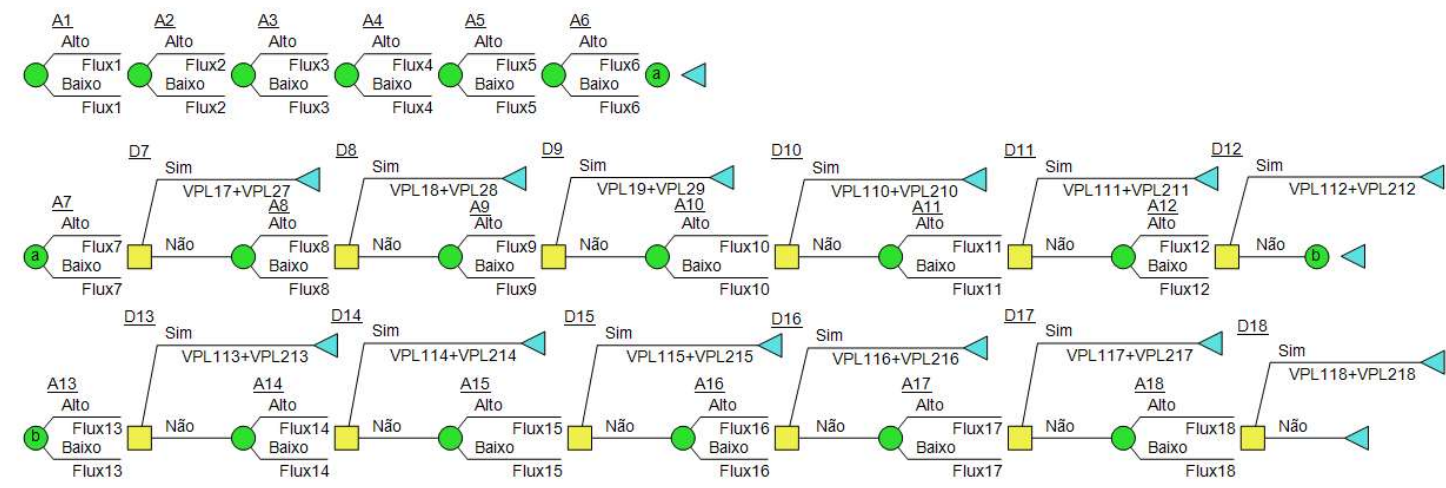

Figura 11 - Estrutura do modelo no DPL TM

Com isso, foram geradas 3 árvores de decisão no qual cada uma traz um VPL e a informação sobre o período ótimo em que devesse iniciar a fase 2. Em todos os cenários os VPL's resultaram positivos, o que indica que o projeto é viável e irá criar valor para os investidores.

E a conclusão que a fase 2 deverá iniciar no final do projeto, no $18^{\circ}$ período. $\mathrm{Na}$ Figura 12 vem a probabilidade das decisões em cada período. Como todos os cenários deram o mesmo resultado, suas probabilidades são iguais.

D7
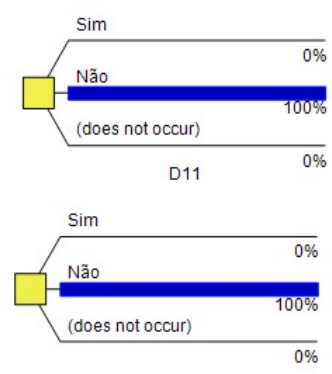

D15

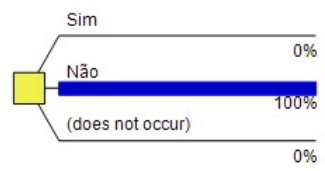

D8

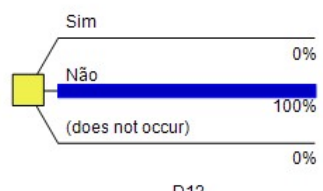

D12

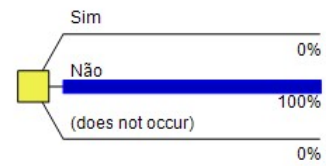

D16

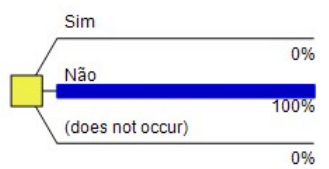

D9

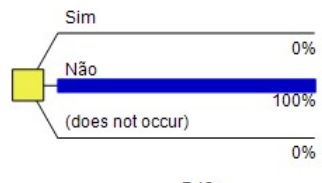

D13

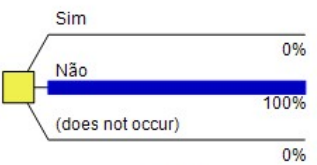

D17

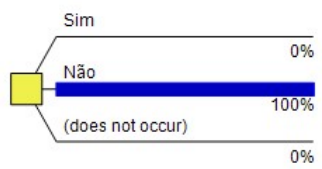

D10
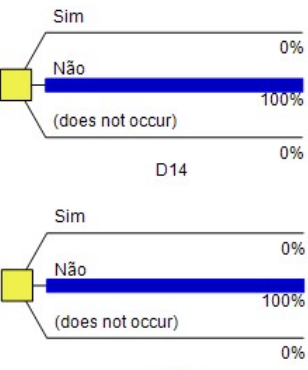

D18

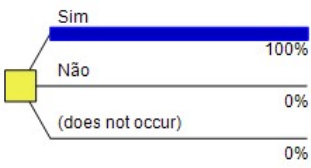

Figura 12 - Probabilidade das decisões dos períodos $7^{\circ}$ ao $18^{\circ}$ nos três cenário. 
Já os VPL's deram todos positivos, mas cada cenário teve um resultado diferente. A tabela 8 mostra os VPL's na fase 1 em cada cenário, depois na fase 2 do $7^{\circ}$ e $18^{\circ}$ período como exemplos, a soma dos VPL's fase 1 e fase 2 , a soma dos valores encontrados no modelo da ferramenta do DPL e, por último, a diferença entre eles. Pode-se concluir que o VPL do modelo está bem próximo do VPL da fase 1 mais o VPL da fase 2 no $18^{\circ}$ período, isso corrobora o resultado do modelo iniciar a fase 2 no $18^{\circ}$ período.

\begin{tabular}{|lccc|}
\hline & Pessimista & Esperado & Otimista \\
\hline VPL Fase 1 & 83.985 & 86.946 & 88.000 \\
VPL Fase 2 - 70 período & 116.492 & 116.265 & 116.372 \\
VPL Fase 2 - 18 0 período & 127.575 & 128.298 & 129.122 \\
\hline \hline VPL Fase 1 + Fase 2 - 70 período & 200.477 & 203.211 & 204.372 \\
VPL Fase 1 + Fase 2 - 18 período & 211.560 & 215.244 & 217.122 \\
VPL DPL Fase 1 + Fase 2 & 212.600 & 216.400 & 218.300 \\
\hline \hline & 12.123 & 13.189 & 13.928 \\
Comparativo (Planilha x DPL) & 1.040 & 1.156 & 1.178 \\
\hline
\end{tabular}

Tabela 8 - Comparativos dos VPL's

Na figura 13, mostra graficamente a comparação entre VPL Fase 1 + Fase $2-7^{\circ}$ período, VPL Fase $1+$ Fase $2-18^{\circ}$ período e VPL DPL Fase $1+$ Fase 2.

\section{Comparativo dos VPL's}

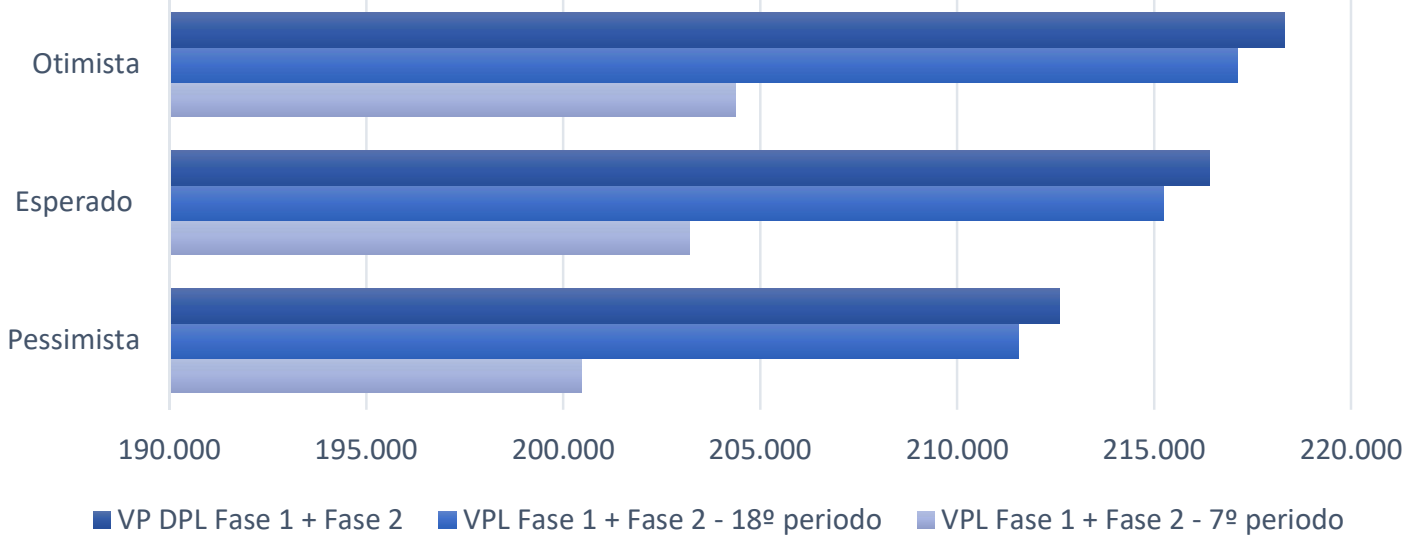

Figura 13 - Comparativo dos VPL's em cada cenário. Elaboração Própria 
Outro ponto que pode ser destacado é que o VPL conforme determinado pela modelagem de opções reais é superior aos VPL's calculados pelo método tradicional do Fluxo de Caixa Descontado realizado nas planilhas. Essa diferença ocorre em função do valor agregado pela flexibilidade gerencial que o projeto apresenta. 


\section{CONCLUSÃO}

O mercado imobiliário é um setor muito rico de informações, no qual podese explorado e correlacionado com opções reais. Essa conexão pode ser feita, porque o mercado em questão envolve variáveis de incerteza e traz flexibilidade nas decisões que envolve o processo como um todo.

No presente estudo foi analisado um empreendimento residencial localizado na zona oeste da cidade do Rio de Janeiro a ser construído em duas fases. Considerou-se que o lançamento e construção da Fase 1 ocorrerá de imediato, e que a empresa tem flexibilidade para escolher o momento ótimo de iniciar a Fase 2 com base na aceitação do mercado da Fase 1 .

Afim de mensurar essa decisão, adotou-se a metodologia das opções reais, no qual se estruturou um modelo para decidir qual seria o melhor momento para lançar a segunda fase. A variável de incerteza adotada foi a Preço do $\mathrm{m}^{2}$ que segue um MGB. Além disso, foi apontado a importância da velocidade de venda na construção dos fluxos de caixa dos projetos, que foi considerada a mesma para ambas as fases. Para isso, determinou-se três cenários, pessimista, esperado e otimista.

Os resultados indicam que para todos os cenários testados a melhor estratégia é de adiar o início da Fase 2 até o último momento, ou seja, que o $18^{\circ}$ mês seria a data ótima. Considerando que a projeção do preço por $\mathrm{m}^{2}$ é sempre crescente e que os custos do investimento são fixos, essa conclusão faz sentido intuitivo.

Por outro lado, observa-se que isso não ocorre na prática pelas incorporadoras, que costumam lançar de imediato expansões de um projeto que teve boa aceitação do mercado. Isso poderia sugerir que elas não estão maximizando o valor do projeto.

Consideramos, no entanto, que as conclusões do modelo podem ter sido impactadas pela premissa de que a velocidade de venda na fase 2 será a mesma da fase 1. Dado que não há nenhuma garantia de que a velocidade de vendas observada na Fase 1 irá se manter constante ao longo dos próximos 18 meses, um adiamento prolongado pode eventualmente prejudicar os resultados do projeto se houver um desaquecimento do mercado imobiliário nesse período. 
Portanto, uma sugestão para trabalhos futuros é incluir a modelagem da velocidade de venda como variável de incerteza de forma a replicar com mais fidelidade o comportamento do mercado. A modelagem da velocidade de venda pode ser baseada na disponibilidade de financiamento no mercado.

Outra alternativa seria uma mudança no projeto da fase 2, alterar, dimensões, metragem, quantidade de quartos por exemplo. Essas alterações podem agregar valor ao projeto e torna-lo mais atrativo ao mercado consumidor. 


\section{BIBLIOGRAFIA}

ABECIP. Associação Brasileira das Entidades de Crédito Imobiliário e Poupança. Disponivel em: https://www.abecip.org.br/imprensa/ noticias/mercado-imobiliario-no-rio-comeca-a-se-recuperar-dacrise. Acessado em: 02 Nov 2020

ABRAINC, Associação Brasileira de Incorporadoras Imobiliárias. Investimento em Imóveis. Disponível em: https://www.abrainc.org.br/wp-content/uploads/2020/07/Investiment o_Imoveis_02_07-1.pdf. Acesso em: 14 Dez. 2020.

ABRAINC, Associação Brasileira de Incorporadoras Imobiliárias. Nível de confiança do empresário do setor imobiliário residencial 3 T20. Disponível em: https://www.abrainc.org.br/wp-content/uploads/ 2020/10/1\%C2\%B0-Pesquisa-Abrainc-Nivel_Confian\%C3\%A7a3T20.pdf. Acesso em: 14 Dez. 2020.

ADEMI-RIO. Associação de dirigentes de empresas do mercado imobiliário. Disponivel em: http://www.ademi.org.br/rubrique.php3?id_rubrique =51. Acessado em 14 dez 2020 .

Almeida, G. L. D., Dias, M. A. G., Brandão, L. E. T., \& Samanez, C. P. M. (2019). Um modelo de opções reais com jogos aplicado ao mercado imobiliário residencial do Rio de Janeiro. Revista Brasileira de Gestão de Negócios, 21(1), 118-135.

BACEN. Banco Central. Focus - Distribuição de Frequência. Fevereiro/2021, Disponivel em: https://www.bcb.gov.br/ controleinflacao/focusdistribuicoesfrequencia. Acessado em: 05 abr 2021

BACEN. Banco Central. Taxa de juros - Selic acumulada no mês. Disponivel em: https://dadosabertos.bcb.gov.br/dataset/4390-taxade-juros---selic-acumulada-no-mes. Acessado em: 01 Mar 2021

Ball, M. (1996). London and property markets: a long-term view. Urban Studies, 33(6), 859-876.

Baptistella, M., Steiner, M. T. A., \& Neto, A. C. (2005). O uso de redes neurais e regressão linear múltipla na engenharia de avaliações: Determinação dos valores venais de imóveis urbanos. Diss., Universidade Federal do Paraná.

Barbosa, L. (2005). Investimento no Mercado Imobiliário: Gerenciamento de Risco e Opções Reais. Dissertação de Mestrado em Engenharia Industrial - Pontifícia Universidade Católica do Rio de Janeiro. 
Bernardi, P. B., \& Hochheim, N. (2002, outubro). Estimativa de vendas em empreendimentos imobiliários utilizando simulação. Anais do Encontro Tecnológico da Engenharia Civil e Arquitetura, Maringá, PR, Brasil, 3.

Black, F., \& Scholes, M. (1973). The Pricing of Options and Corporate Liabilities. The Journal of Political Economy, 81(3), 637-654. doi: https://doi.org/10.1086/260062

Brandão, L. E., Dyer, J. S., \& Hahn, W. J. (2005). Using binomial decision trees to solve real-option valuation problems. Decision Analysis, 2(2), 69-88.

BRASIL. Lei n 4.380, de 21 de agosto de 1964. Senado Federal, Brasília, D. F. Diário Oficial da União, 1988. Disponível em: http://www.planalto.gov.br/ccivil_03/ LEIS/L4380.htm. Acesso em: 23 Nov. 2020.

Caporal, A., \& Brandão, L. E. T. (2008). Avaliação de uma Unidade de Geração de Energia Através da Teoria de opções Reais. BBRBrazilian Business Review, 5(2), 108-127.

Cappozza, D., \& Li, Y. (1994). The intensity and timing of investment: the case of land. The American Economic Review, 84(4), 889-904.

Cauley, S. D., \& Pavlov, A. D. (2002). Rational delays: the case of real estate. Journal of Real Estate Finance and Economics, 24(1/2), 143165.CBIC. (2020). Câmara Brasileira da Indústria da Construção. Coletiva de Impresa. Indicadores Imobiliários Nacionais - 3T 2020 [Press release]. Retrieved from http://www.cbicdados.com.br/media/ anexos/INDICADORES_MERC_IMOB_3T2020_vs23nov20.pdf

Copeland, T., \& Antikarov, V. (2001). Real options (No. BOOK). New York: Texere.

Cox, J. C., Ross, S. A., \& Rubinstein, M. (1979). Option pricing: A simplified approach. Journal of Financial Economics, 7(3), 229-263. doi: https://doi.org/10.1016/0304-405X(79)90015-1

CRECI, Conselho Regional de Corretores de Imóveis. Nossa história. Disponivel em: https://creci-rj.gov.br/nossa-historia/. Acesso em: 19 Jan. 2021.

Dixit, A. K., \& Pindyck, R. S. (1994). Investment under Uncertainty. Princeton: Princeton University Press.

Ehrhardt, M. C., \& Brigham, E. F. (2013). Administração Financeira - Teoria e Prática (13a ed.): Cengage Learning.

FIPEZAP, Indice do Preço dos Imoveis, divulgado pela Zapimoveis, Disponievel em https://fipezap.zapimoveis.com.br/. Acessado em: 15 Fev 2021 
Fortunato, G., Brandão, L. E. T., Rozenbaum, S., \& Rebello, A. P. (2008). Valor da Opção de Abandono em Lançamentos Imobiliários Residenciais. RAC-Eletrônica, 2(3), p. 531-545.

Freitas, A., \& Brandão, L. (2010). Real options valuation of e-learning projects. International journal on e-learning, 9(3), 363-383.

Grenadier, S. R. (1996). The Strategic Exercise of Options: Development Cascades and Overbuilding in Real Estate Markets. Journal of Finance, 51(5), 1653-1679.

Imobiliário no Brasil, O. C. (2007). caracterização e desafios. FGV Projetos. São Paulo: FGV.

Lagosto 1962. Disponível em: http://www.planalto.gov.br/CCIVIL_03/leis/ 1950-1969/L4116.htm. Acessado em: 20 Nov. 2020.

Matos, D., \& Bartkiw, P. I. N. (2013). Introdução ao mercado imobiliário. Curitiba: Instituto Federal de Educação, Ciência e Tecnologia-Paraná-Educação a distância.

Medeiros, P. Y. (2008, May). Aplicação de opções reais no mercado imobiliário residencial com enfoque na cidade do Rio de Janeiro. In I Encontro Brasileiro de Finanças.

Merton, R. C. (1973). Theory of Rational Option Pricing. The Bell Journal of Economics and Management Science, 4(1), 141-183. doi: https://dx.doi.org/10.2307/3003143

Quigg, L. (1993). Empirical testing of real option - pricing models. The Journal of Finance, 48(2), 621-641.

Resende, M. F. D. C. (2008). O circuito finance-investimento-poupançafunding em economias abertas. Brazilian Journal of Political Economy, 28(1), 136-154.

Ribeiro, F. S. M. (2004). Avaliação de projetos de incorporação imobiliária sob incerteza-uma abordagem por opções reais (Doctoral dissertation, Dissertação de Mestrado não-publicada, Pontifícia Universidade Católica do Rio de Janeiro, Rio de Janeiro, RJ, Brasil).

Rocha, K. M. (2006). Três Ensaios sobre a Metodologia de Apreçamento de Ativos utilizando Opções Reais. Rio de Janeiro, Brasil.

SECOVIRIO, Sindicato das Empresas de Compra, Venda, Locação e Administração de Imóveis e dos Condomínios Residenciais e Comerciais em todo o Estado do Rio de Janeiro. Panorama do Mercado Imobiliário - Rio de Janeiro, 2019. Disponivel em: https://www.yumpu.com/pt/document/read/63075440/panorama-domercado-imobiliario-do-rio-de-janeiro-2019-10-anos-secovirio, Acessado: 02 Nov 2020 
SECOVIRIO, Sindicato das Empresas de Compra, Venda, Locação e Administração de Imóveis e dos Condomínios Residenciais e Comerciais em todo o Estado do Rio de Janeiro. Revista Cenário Mercado Imobiliário - Rio de Janeiro, 2020. Disponivel em: https://www.yumpu.com/pt/document/read/64662010/cenario-riode-janeiro-2020-secovirio Acessado em: 02 Nov 2020

Titman, S. (1985). Urban Land Prices Under Uncertainty. The American Economic Review, 75(3), 505-514.

Williams, J. (1991). Real State Development as an Option. Journal of Real Estate Finance and Economics, 4(2), 191-208. 


\section{ANEXO A: FLUXO DE CAIXA - CENÁRIO OTIMISTA}

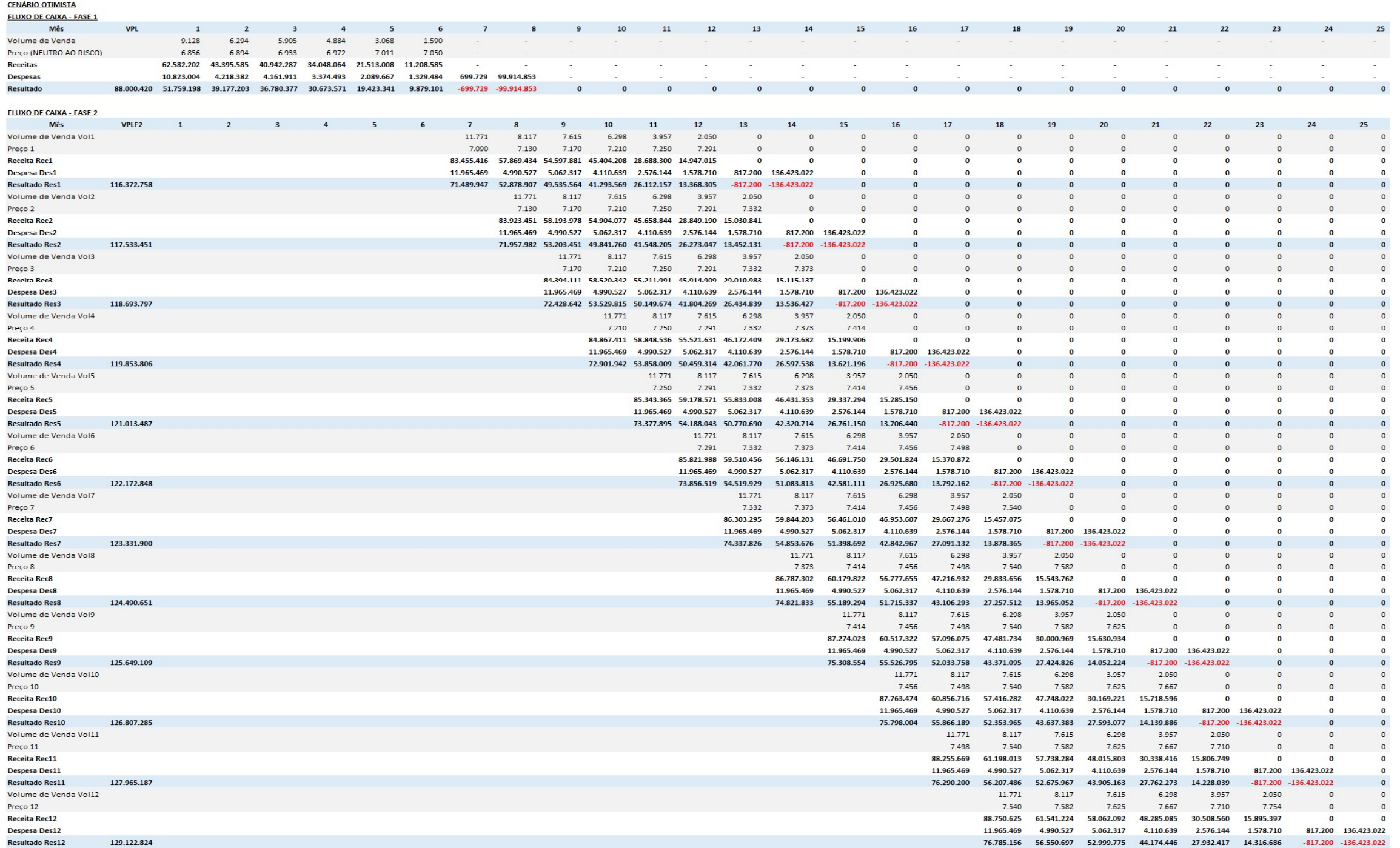


ANEXO B: FLUXO DE CAIXA - CENÁRIO ESPERADO

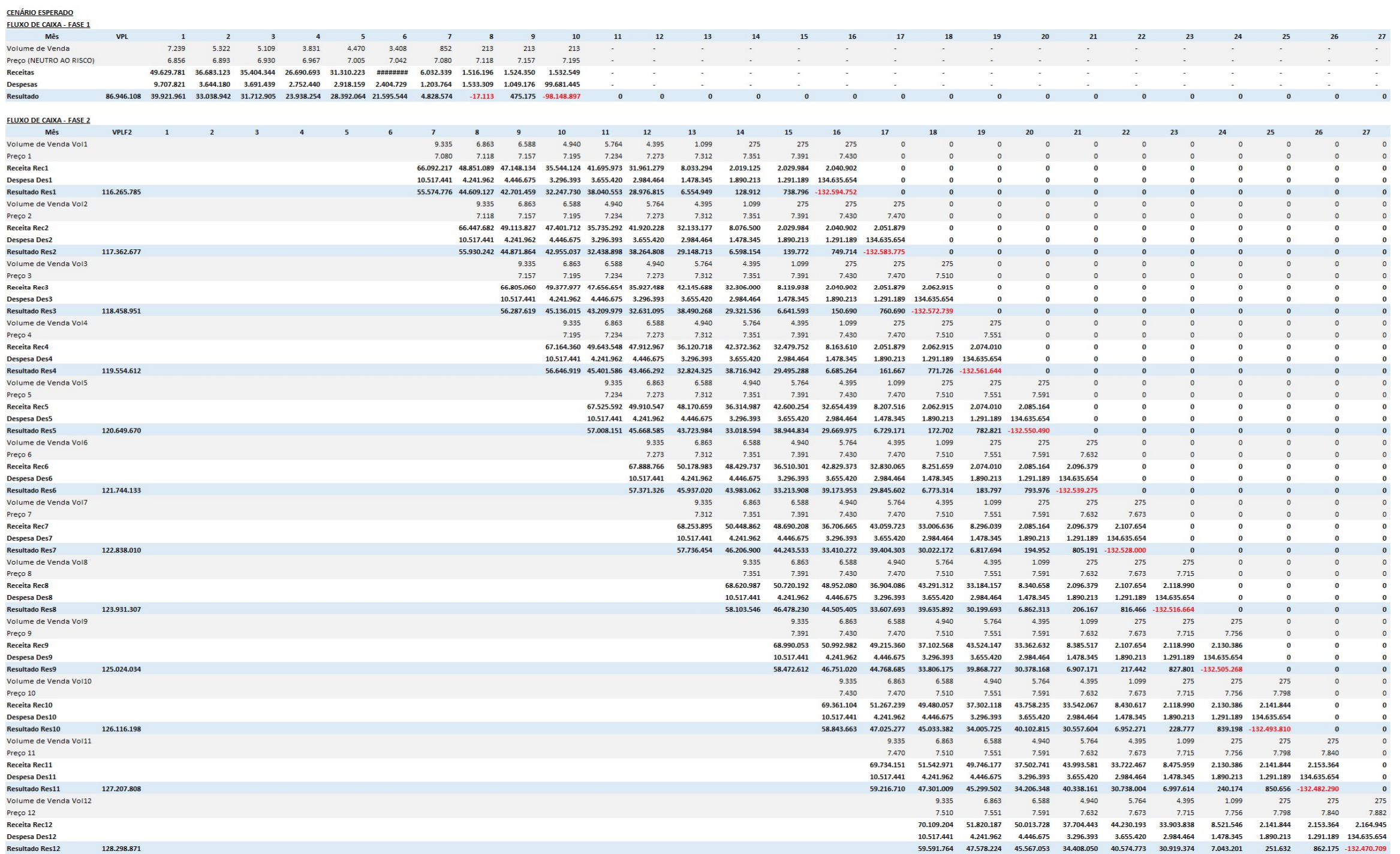




\section{ANEXO C: FLUXO DE CAIXA - CENÁRIO PESSIMISTA}

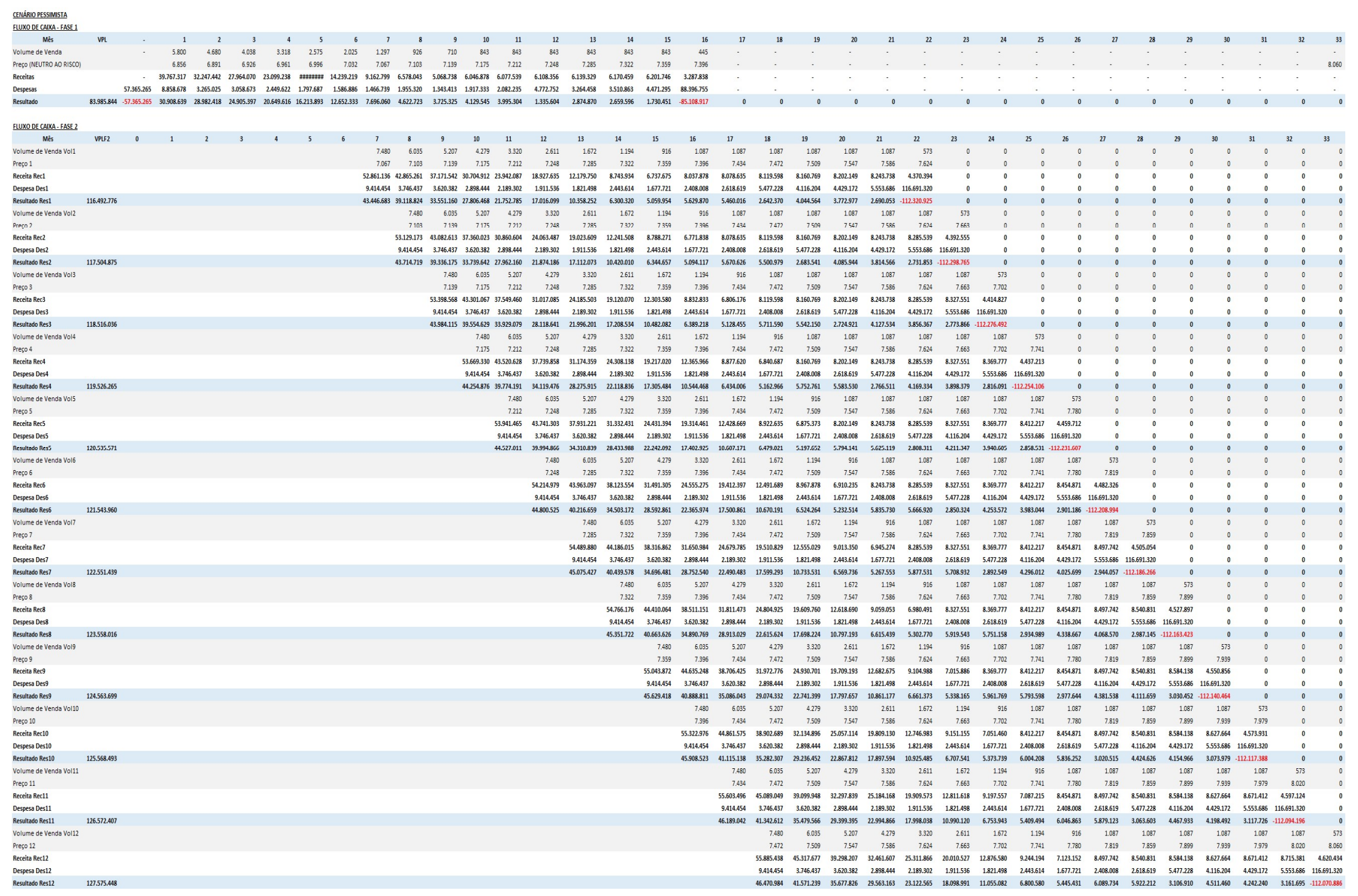

